\title{
Forecast Design in Monetary Capital Stock Measurement
}

by

William Barnett, Unja Chae, and John Keating

University of Kansas

August 21, 2005 


\section{ABSTRACT}

We design a procedure for measuring the United States capital stock of money implied by the Divisia monetary aggregate service flow, in a manner consistent with the present-value model of economic capital stock. We permit non-martingale expectations and time varying discount rates. Based on Barnett's (1991) definition of the economic stock of money, we compute the U.S. economic stock of money by discounting to present value the flow of expected expenditure on the services of monetary assets, where expenditure on monetary services is evaluated at the user costs of the monetary components. As a theoretically consistent measure of money stock, our economic stock of money nests Rotemberg, Driscoll, and Poterba's (1995) currency equivalent index as a special case, under the assumption of martingale expectations. To compute the economic stock of money without imposing martingale expectations, we define a procedure for producing the necessary forecasts based on an asymmetric vector autoregressive model and a Bayesian vector autoregressive model. In application of this proposed procedure, Barnett, Chae, and Keating (2005) find the resulting capital-stock growth-rate index to be surprisingly robust to the modeling of expectations. Similarly the primary conclusions of this supporting paper regard robustness.

We believe that further experiments with other forecasting models would further confirm our robustness conclusion. Different forecasting models can produce substantial differences in forecasts into the distant future. But since the distant future is heavily discounted in our stock formula, and since alternative forecasting formulas rarely produce dramatic differences in short term forecasts, we believe that our robustness result obviates prior concerns about the dependency of theoretical monetary capital stock computations upon forecasts of future expected flows. Even the simple martingale forecast, which has no unknown parameters and is easily computed with current period data, produces a discounted stock measure that is adequate for most purposes. Determining an easily measured extended index that can remove the small bias that we identify under the martingale forecast remains a subject for our future research.

At the time that Milton Friedman (1969) was at the University of Chicago, the "Chicago School" view on the monetary transmission mechanism was based upon the wealth effect, called the "real balance effect" or "Pigou (1943) effect," of open market operations. Our research identifies very large errors in the wealth effects computed from the conventional simple sum monetary aggregates and makes substantial progress in the direction of accurate measurement of monetary-policy wealth effects.

Keywords: Monetary aggregation, Divisia money aggregate, economic stock of money, user cost of money, currency equivalent index, Bayesian vector autoregression, asymmetric vector autoregression.

JEL Classifications: E4, E5, C43, G12 


\section{Introduction}

Conventionally, central banks have measured the official monetary aggregates by adding up the nominal quantities of components included in the monetary aggregates. The resulting monetary aggregate is called the simple sum aggregate or simple sum index (SSI). But the SSI has long been questioned as a measure of money stock, because of its disconnect from microeconomic aggregation and index number theory. The simple sum aggregate implicitly assumes that all monetary components are perfect substitutes with all monetary components having equal linear weights. Since monetary assets began yielding interest over half a century ago in the United States, with different interest rates paid on different monetary assets, perfect substitutability among monetary assets with equal weights has become an unrealistic assumption. ${ }^{1}$

Respect within the profession for the simple sum monetary aggregates has declined, as inclusion of interest-bearing assets has grown within the monetary aggregates---for good reason. The nature of the problem was anticipated clearly by Milton Friedman through the work of many of his students in his money workshop at the University of Chicago and through the following statement in Friedman and Schwartz (1970, pp. 151-152):

"This [simple summation] procedure is a very special case of the more general approach. In brief, the general approach consists of regarding each asset as a joint product having different degrees of 'moneyness,' and defining the quantity of money as the weighted sum of the aggregated value of all assets, the weights for individual assets varying from zero to unity with a weight of unity assigned to that asset or assets regarded as having the largest quantity of 'moneyness' per dollar of aggregate value. The procedure we have followed implies that all weights are either zero or unity.The more general approach has been suggested frequently but experimented with only occasionally. We conjecture that this approach deserves and will get much more attention than it has so far received."

In a footnote, Friedman and Schwartz further referenced the dissertations of many of Friedman's

\footnotetext{
${ }^{1}$ Some have argued that money has always yielded implicit interest in terms of the yield on tax evasion and on other forms of illegal use of cash. Theoretical discussions of interest bearing money have been in the literature since Wicksell (1898).
} 
students, who had attempted to deal with the problem, but were not able to establish the needed connection with the relevant literature on aggregation and index number theory. These unsolved problems had been a source of concern since Hawtrey (1930), but did not become a serious source of difficulty to central banks until the 1970s. The first clear recognition of the relevancy of aggregator functions to the solution of the problem was Chetty $(1969,1972)$, but he similarly did not connect his aggregator function (a CES function) with a statistical index number that could track his aggregator function nonparametrically. ${ }^{2}$

A theoretically appropriate alternative to the simple sum aggregate is the Divisia monetary aggregate derived by Barnett (1980). By taking into account the different user-cost prices of monetary components, the Divisia monetary aggregate does not require perfect substitutability among monetary assets and reflects the properly weighted contributions of all monetary components to the economy's flow of monetary services. However, the Divisia aggregate measures monetary service flows, not monetary stock. While most variables in economic theory are flows, monetary stock is needed for some purposes. For instance, the wealth variable in intertemporal Fisherine wealth constraints should be entered as money stock. Similarly the Pigou (1943) wealth effects of monetary policy require stock explanatory variables. In fact, at the time that Milton Friedman (1969) was at the University of Chicago, the "Chicago School" view on the monetary transmission mechanism was based entirely upon the wealth effect, called the "real balance effect," of open market operations. For a modern treatment of that transmission mechanism, see Ireland (2001). Our research identifies very large errors in the wealth effects computed from the conventional simple sum monetary aggregates and makes substantial progress in the direction of accurate measurement of monetary-policy wealth effects.

The objective of this paper is to measure money stock in a manner consistent with the aggregation-theoretic foundations of the Divisia service-flow aggregate. We compute the first theory-based economic stock of money not requiring the assumption of martingale expectations. In this paper, we define the design of the forecasting model used in producing the economic capital stock of money, computed as the

\footnotetext{
${ }^{2}$ Other early research that recognized the problem, but did not succeed in connecting with statistical index number theory, includes Gurley (1960, pp. 7-8), Friedman and Meiselman (1963, p. 185), Kane
} 
discounted present value of the service flow. ${ }^{3}$ Results with the resulting new stock aggregate are in Barnett, Chae, and Keating (2005).

Barnett (1991b) showed that the monetary stock implied by the Divisia flow aggregate is the discounted present value of expected monetary-service-flow expenditure, with expenditure on monetary services being evaluated at user-cost prices. Following Barnett, we call the money stock implied by the Divisia monetary service flow---the "economic stock of money." In addition to its direct derivation from microeconomic theory, the economic monetary stock (ESM hereafter) has several attractive properties. First, the ESM is consistent with asset pricing theory. In particular, the formula for ESM is consistent with valuation of a cash-flow generating asset by discounting the flow to present value. Second, the economic monetary stock provides a general capital stock formula that nests the simple sum index and the currency equivalent (CE) index (of Rotemberg (1991) and Rotemberg, Driscoll, and Poterba (1995)) as special cases. In particular, under the assumption of martingale expectations, the ESM index reduces to the CE index (Barnett (1991b)), with the additional assumption of zero return-yield rates for all monetary assets, ESM reduces to the simple sum index.

The assumptions of zero return-yield rates and of martingale expectations are both highly implausible. We make neither of those assumptions. We compute the ESM using forecasts of the future variables in the formula. Our forecasts are based upon an asymmetric vector autoregressive model (AVAR) and a Bayesian vector autoregressive model (BVAR). For purposes of comparison, we also compute the ESM using actual realized future data within sample. Barnett, Chae, and Keating (2005) compare the estimated ESM with the simple sum index (SSI) and the CE index. They thereby investigate the measurement biases inherent in the SSI and the CE index. Our use of VAR forecasting is part of our measurement procedure, rather than a means of judging policy relevancy. Our approach is aggregation-theoretic rather than policy-focused. But VAR comparisons of Divisia and simple sum

(1964), Ford and Stark (1967), Steinhauer and Chang (1972), Lee (1972), Bisignano (1974), Moroney and Wilbratte (1976) and Barth, Kraft, and Kraft (1977).

${ }^{3}$ Asset pricing theory, which concludes that assets will be priced by markets at the discounted present value of the asset's generated flow, is not without its own implicit assumptions. For a revealing discussion of the implicit assumptions, see section 6.3 of Blanchard and Fischer (1989). 
monetary aggregation for policy purposes do exist. See Schunk (2001). ${ }^{4}$

Use of the economically correct measure for monetary stock can improve the quality of empirical research on wealth effects caused by changes in the expected monetary service flow induced by policy shifts.

\section{Microfoundations of Consumer Demand for Money}

\subsection{Overview}

In this section we review the theoretical foundations for a representative consumer's money demand under risk neutrality in accordance with Barnett (1980). Strictly speaking, it would be best to derive the results in continuous time, and then produce a discrete time approximation to account for the fact that the existing data is available only in discrete time, with interest rates paid at ends of periods. ${ }^{5}$ In continuous time, interest is paid instantly and therefore requires no discounting within periods. In fact, the literature on the Törnqvist discrete time approximation to the Divisia index evolved in that manner. But direct derivation in discrete time, while less elegant, is considerably more concise than the two stage procedure of derivation first in continuous time and then approximation in discrete time.

We first define the variables for period $s$, where $t$ is the current period, and $T$ is the length of the planning horizon for $t \leq s \leq t+T$ :

$\mathbf{c}_{\mathrm{s}}=$ vector of per capita planned consumption of goods and services,

$\mathbf{p}_{\mathrm{s}}=$ vector of goods and services expected prices and of durable goods expected rental prices,

$p_{\mathrm{s}}^{*}=$ the true cost of living index, ${ }^{6}$

\footnotetext{
${ }^{4}$ For comparisons of Divisia monetary aggregates with other monetary aggregates and across levels of aggregation by other methods, see Barnett (1982), Barnett, Fisher, and Serletis (1992), and Barnett, Offenbacher, and Spindt (1984).

${ }^{5}$ Clearly the economy exists in continuous time, since discrete time models, interpreted literally, imply that markets open and close only on the boundaries of the discrete time intervals. The sequence of boundary points is a measure zero subset of the real line. Hence a literal interpretation of discrete time economic models would conclude that the economy exists "almost nowhere" along the time axis.

${ }^{6}$ We use the term "true cost of living index" in the formal manner rigorously defined in the microeconomic aggregation theory literature. The most common special case results if $v\left(\mathrm{c}_{t}\right)$ is linearly homogeneous. In that case, the true cost of living index is the unit cost function induced by $v\left(c_{t}\right)$. Regarding nonparametric statistical approximation to the theoretical index, a large literature exists. At the present time, the Fisher ideal index, which is the geometric mean of the Laspeyres and Paasche index, is gaining increasing acceptance by data production governmental agencies, such as
} 
$\mathbf{m}_{s}=$ vector of planned real balances of monetary assets with components $m_{i s}(i=1,2, \ldots ., n)$,

$r_{i s}=$ the expected nominal holding period yield on monetary asset $i$,

$L_{s}=$ planned labor supply,

$w_{s}=$ the expected wage rate,

$B_{s}=$ planned holdings of the benchmark asset,

$R_{S}=$ the expected nominal holding-period yield on the benchmark asset,

$I_{s}=$ all other sources of income.

The benchmark asset is defined to be a pure investment asset providing financial yield $R_{s}$ but no liquidity or other services. ${ }^{7}$ A representative economic agent holds the asset solely as a means of accumulating and of transferring wealth between periods. Thus under risk neutrality, the benchmark rate $R_{s}$ will be the maximum expected holding-period yield in the economy in period $s$.

During period $t$, let the representative consumer's intertemporal utility function, $\mathcal{U}_{t}$, be weakly

separable in the block of each period's consumption of goods and monetary assets, so that an exact monetary

the Department of Commerce in the United States. The Fisher ideal index is included within Diewert's (1976) class of "superlative index numbers" and is unbiased, since it cancels out the upwards bias of the Laspeyres index with the downwards bias of the Paasche index.

There are two possible sources of nonuniqueness to the theoretically exactly correct consumer price index of aggregation theory: (i) nonhomotheticity of $v\left(c_{t}\right)$ and (ii) heterogeneity across economic agents. Nonhomotheticity produces dependency upon the arbitrary choice of a base welfare level or the similarly arbitrary decision to chain that welfare level. Hence the true cost of living index is unique in theory only conditionally upon the treatment of the reference welfare level. Under linear homogeneity of $v\left(c_{t}\right)$, that arbitrary dependency disappears and the true cost of living index is unique. See, e.g., Samuelson and Swamy (1974). But Barnett (2005) has found another source of nonuniqueness. Under heterogeneity of tastes across groups of economic agents, Barnett found that there are two exactly correct consumer price aggregates: one for deflating nominal to real consumption expenditure, and one for deflating nominal to real monetary balances. We do not explicitly consider those complications in this paper.

${ }^{7}$ In the growth model literature, the benchmark asset often is viewed to be human capital. In a world without slavery, there is no secondary market in the stock of labor, only a rental market in its services, which are embedded within individuals. While this imputation is debatable (some investment in human capital is for personal "consumption" of knowledge, there is no question that any credible proxy for the rate of return on the benchmark asset would have to be higher than the rate of return on any liquid asset having a good secondary market. The most sophisticated approach currently available for producing that proxy involves extracting and adding up all risk-free premia, including liquidity premia, existing within the rate structure of assets having a market. For the design of such a proposed procedure, see Barnett (2005). 
aggregator function, $\mathrm{u}$, exists: ${ }^{8}$

$$
\mathcal{U}_{t}=\mathcal{U}\left(u\left(\mathbf{m}_{t}\right), u_{t+1}\left(\mathbf{m}_{t+1}\right), \ldots, u_{t+T}\left(\mathbf{m}_{t+T}\right) ; v\left(\mathbf{c}_{t}\right), \mathrm{v}_{t+1}\left(\mathbf{c}_{t+1}\right), \ldots, v_{t}\left(\mathbf{c}_{t+T}\right) ; B_{\mathrm{t}+T}\right)
$$

The function $\mathrm{u}$ is assumed to be linearly homogeneous, which is a sufficient condition in aggregation theory for $u$ to serve simultaneously as the monetary asset category utility function and the monetary asset quantity aggregator function. Dual to the category utility function of non-monetary goods and services, $v_{\mathrm{s}}\left(\mathbf{c}_{\mathrm{s}}\right)$, there

exists true cost of living index, $p_{\mathrm{s}}^{*}=p_{\mathrm{s}}^{*}\left(\mathbf{p}_{\mathrm{s}}\right)$, which can be used to deflate nominal values to real values during period $s$.

Maximization of intertemporal utility is subject to the following budget constraints for $s=t, \ldots, t+T$ :

$$
\mathbf{p}_{S}^{\prime} \mathbf{c}_{s}=w_{s} L_{s}+\sum_{i=1}^{n}\left[\left(1+r_{i, s-1}\right) p_{s-1}^{*} m_{i, s-1}-p_{s}^{*} m_{i s}\right]+\left[\left(1+R_{s-1}\right) p_{s-1}^{*} B_{s-1}-p_{s}^{*} B_{s}\right]+I_{S}
$$

\subsection{User Cost of Money}

Money is a durable good. The cost of using the services of a durable good or asset during one period is the user cost price or rental price. ${ }^{9}$ Barnett $(1978,1980)$ derived the user cost price of the services of monetary assets by recursively combining the $T+1$ multi-period budget constraints, (2.2), into the single discounted Fisherine wealth constraint,

$$
\begin{aligned}
& \sum_{s=t}^{t+T}\left(\frac{\mathbf{p}_{s}^{\prime}}{\rho_{S}}\right) \mathbf{c}_{s}+\sum_{s=t}^{t+T} \sum_{i=1}^{n}\left[\frac{p_{s}^{*}}{\rho_{s}}-\frac{p_{s}^{*}\left(1+r_{i s}\right)}{\rho_{s+1}}\right] m_{i s}+\sum_{i=1}^{n} \frac{p_{s+T}^{*}\left(1+r_{i, t+T}\right)}{\rho_{t+T+1}} m_{i, t+T}+\frac{p_{s+T}^{*}}{\rho_{s+T}} B_{t+T} \\
= & \sum_{s=t}^{t+T}\left(\frac{w_{s}}{\rho_{s}}\right) L_{s}+\sum_{i=1}^{n}\left(1+r_{i, t-1}\right) p_{t-1}^{*} m_{i, t-1}+\left(1+R_{t-1}\right) A_{t-1} p_{t-1}^{*} .
\end{aligned}
$$

From that factorization of the intertemporal constraint, we see that the forward user cost of the services of the monetary asset $m_{i}$ in period $s$ is

\footnotetext{
${ }^{8}$ Under Hicksian aggregation, requiring relative prices to be constant over time, weak separability is not necessary for aggregation. But so long as relative prices are free to vary without constraints over time, weak separability is a necessary condition for aggregation. The fact, which is well established in aggregation theory, going back to the work of Strotz, Gorman, Leontief, and Samuelson, is well presented rigorously in Green (1964, Theorem 4).

${ }^{9}$ The concept of the user cost of a durable's service flow is usually associated with the important work of Jorgenson (1967), although has been understood in the literature since early in the twentieth century. See Barnett and Serletis (2000, p. xxix) regarding the role of Jorgenson's research in this literature.
} 


$$
\psi_{i s}=\frac{p_{s}^{*}}{\rho_{s}}-\frac{p_{s}^{*}\left(1+r_{i s}\right)}{\rho_{s+1}}
$$

where the discount rate for period $s$ is

$$
\rho_{s}=\left\{\begin{array}{ccc}
1 & \text { for } & s=t \\
\prod_{u=t}^{s-1}\left(1+R_{u}\right) & \text { for } & s>t
\end{array} .\right.
$$

As a result, the current period nominal user cost of monetary asset $m_{i}$ is

$$
\psi_{i t}=p_{t}^{*} \frac{R_{t}-r_{i t}}{1+R_{t}}
$$

while the corresponding real user cost of monetary asset $\mathrm{m}_{\mathrm{i}}$ is $\psi_{i t}^{r}=\psi_{i t} / p_{t}^{*}$.

Understanding equation (2.6) is very important, and oddly to this day is often misunderstood. For a clear discussion, see Barnett (1983). ${ }^{10}$ Consider the following case: interest rates measured as real rates of return, own rate of interest zero, and continuous time. In continuous time, the discounting across the current discrete time interval does not apply. Hence the denominator of (2.6) is eliminated (as can be shown from derivation in continuous time or by letting the time interval converge to a point in time). If the own rate of return on a monetary asset is zero, then $r_{i t}$ disappears, leaving only $R_{t}$. In real terms, that rate of return equals its nominal value minus the inflation rate. While that result is applicable to non-interest-bearing money (e.g., currency) in continuous time, that special case often is erroneously imputed to interest bearing monetary assets to the present day. ${ }^{11}$

\subsection{Conditional Current Period Optimization}

It is customary in this literature to decompose decision ((2.1) subject to (2.2)) into a two stage decision, with the first stage budgeting total service flows over periods intertemporally and the second stage allocating the budgeted total flow for a period over assets contemporaneously within that period. Our assumption of intertemporal weak separability in equation (2.1) permits that decomposition, as mentioned in section 3 below. That two-stage decomposition can simplify the exposition and derivation of single-period

\footnotetext{
${ }^{10}$ Also see Donovan (1978) for further correct discussion.

${ }^{11}$ In fact that imputation is obviously wrong, when monetary assets themselves yield interest, since the entire real rate of return on the benchmark asset is then not foregone, to consume the services of
} 
aggregate flow indices, such as the contemporaneous Divisia monetary aggregates, by requiring only static optimization in the second stage. But we need the full decision for asset pricing purposes, since markets cannot price stocks independently of flows extending into the future. Intertemporal weak separability cannot be used to separate capital asset pricing from future flows.

But it should be observed that our assumption of intertemporal separability may be related to the "equity premium puzzle" problem of inadequate imputation of risk premia under risk aversion. Although we assume risk neutrality in the current paper, extension to risk aversion without intertemporal separability could be based upon Barnett and Wu (2005).

\subsection{The Supply Side}

In this paper, we present only the theory produced on the demand side by consumer choice. But in many parts of the world, the National Accounts contain related indirect measurement of financial intermediary services. ${ }^{12}$ This admirable literature, highly relevant to measurement of inside money services, is associated with this research through its supply side analogue. The supply side theory can be found in Barnett (sections 5.3, 6.2, 7.2, 8.2, 11). It should be observed that inside money, measured correctly in this manner as value added in banking, is far different from the conventional official measure by central banks, which routinely subtract outside money from the simple sum monetary aggregates to acquire what central banks often called "inside money." For empirical research results with the aggregation-theoretic supply-side data, see Barnett, Hinich, and Weber (1986). Also see Hancock (1991).

\section{Economic Aggregation and Index Number Theory}

Let $\psi_{t}=\left(\psi_{1 t}, \ldots, \psi_{n t}\right)^{\prime}$, and define total current period expenditure on monetary services during

period $t$ to be $(T E)_{t}=\psi_{t}^{\prime} \mathbf{m}_{t}^{*}$, where $\mathbf{m}_{t}^{*}$ is the optimized value of $\mathbf{m}_{t}$ from maximizing (2.1) subject to (2.2).

Then the exact monetary aggregate, $M_{t}=\mathrm{u}\left(\mathbf{m}_{t}^{*}\right)$, can be tracked without error by the Divisia index (Barnett, $1982 \mathrm{~b}, 1983)$ in the continuous time analog to $((2.1),(2.2))$ :

money, when money has a nonzero own rate of return, and hence the real rate of return on the benchmark cannot be the opportunity cost of the services of monetary assets.

${ }^{12}$ National accounts also make use of various methods of decomposing changes, as into volume changes and nominal holding gains. On the supply side, double deflation is used to measure value 


$$
\frac{d \log M_{t}}{d t}=\sum_{i=1}^{n} w_{i t} \frac{d \log m_{i t}^{*}}{d t}
$$

where $w_{i t}=\frac{\psi_{i t} m_{i t}^{*}}{(T E)_{t}}$ is the $i^{\prime}$ th asset's share in expenditure on all monetary assets' service flows at instant of time t.

It is important to understand that the aggregation-theoretic monetary service flow measures all services of money other than investment yield. If investment yield were a "monetary service," then all assets yielding investment return, including coal mines and land, would be money. This fact has long been recognized in the literature, and Pesek and Saving (1967) even conclude that any assets yielding an investment rate or return cannot be monetary assets at all. But aggregation theory permits us to remove the nonmonetary services and measure the residual. Any services other than investment yield that we do not wish to call monetary services must be measured and included in the interest yield to be removed from the measured monetary service flow. For example, the free dishes sometimes offered by banks as an incentive to open an account can be monetized and added to the interest yield to remove their services from $M_{t}$.

It is also important to recognize that the aggregate monetary service flow $M_{t}=\mathrm{u}\left(\mathbf{m}_{t}^{*}\right)$ is a concave increasing function of the vector of stocks, $\mathbf{m}_{t}^{*}$. The aggregator function, $\mathrm{u}$, is nonlinear and implies no assumption of proportionality between stocks and flows. The assumption of existence of the function, $\mathbf{u}\left(\mathbf{m}_{t}^{*}\right)$, does imply the existence of a preference preordering over the vectors of stocks. Without a time subscript on the function $\mathrm{u}$, we are assuming that the services of the stocks, although not necessarily proportional to the stock, are stable over time. There has been some research into extensions to incorporate technological change that could produce changing service properties of the assets over time and time-dependent tastes that could cause the function u to vary for other reasons. See, for example, Barnett and Serletis (2000, chapter 2, section 6.1 and chapter 3 , sections 8 and 10).

In discrete time, the Törnqvist second order approximation to the Divisia index is

$$
\log M_{t}-\log M_{t-1}=\sum_{i=1}^{n} \bar{w}_{i t}\left(\log m_{i t}^{*}-\log m_{i, t-1}^{*}\right)
$$

added. The assumptions and procedures needed for such accounting decompositions are discussed in 
where $\bar{w}_{i t}=\left(w_{i t}+w_{i, t-1}\right) / 2$. Equation (3.2) defines the discrete "Divisia monetary aggregate," which measures the aggregate monetary service flow during period $t$, as appropriate to our discrete time formulation of the model. This Törnqvist approximation, (3.2), to the continuous time Divisia index, (3.1), is in the class of superlative index numbers defined by Diewert (1976) to provide a chained quadratic approximation to the continuous time index.

\subsection{Definition of the Economic Stock of Money}

The economic stock of money, as defined by Barnett (1991b), follows immediately from the manner in which monetary assets are found to enter the derived wealth constraint, (2.3). As a result, the formula for the economic stock of money (ESM) is

$$
V_{t}=\sum_{s=t}^{\infty} \sum_{i=1}^{n}\left[\frac{p_{s}^{*}}{\rho_{S}}-\frac{p_{S}^{*}\left(1+r_{i s}\right)}{\rho_{s+1}}\right] m_{i s} .
$$

As is evident from (3.3), the economic stock of money is found to be the discounted present value of expenditure flow on the services of all monetary assets, with each asset priced at its user cost. Let $M_{i s}$ be the nominal balance of monetary asset $i$ in period $s$, so that $M_{i s}=p_{s}^{*} m_{i s}$. Using definition (2.5), $V_{t}$ becomes

$$
V_{t}=\sum_{s=t}^{\infty} \sum_{i=1}^{n}\left[\frac{R_{s}-r_{i s}}{\prod_{u=t}^{s}\left(1+R_{u}\right)}\right] M_{i s}
$$

A mathematically equivalent alternative form of (3.4) can be derived from quantity and user cost flow aggregates, discounted to present value. Dual to any exact quantity flow aggregate, there exists a unique price aggregate. The price aggregate equals the minimum cost of consuming one unit of the quantity aggregate. Let $\Psi_{t}=\Psi\left(\psi_{t}\right)$ be the nominal user cost aggregate that is dual to the exact, real monetary quantity aggregate, $M_{t}$. By Fisher's factor reversal, the product of the quantity and user cost price aggregate must equal expenditure on the components. It follows that

$$
(T E)_{s}=\sum_{i=1}^{n} m_{i s} \psi_{i s}=M\left(\mathbf{m}_{s}\right) \Psi\left(\psi_{s}\right),
$$

where $(T E)_{s}$ is total nominal expenditure on the monetary services of all monetary components.

section 11 of Barnett (1987). 
Alternatively, instead of using real quantities and nominal user costs, we can use nominal quantities and real user costs to acquire

$$
(T E)_{s}=\sum_{i=1}^{n} M_{i s} \psi_{i s}^{r}=M\left(\mathbf{M}_{S}\right) \Psi\left(\Psi_{S}^{r}\right)
$$

where $\psi_{i s}^{r}=\psi_{i s} / p_{s}^{*}=\frac{R_{s}-r_{i s}}{1+R_{s}}$ is the real user cost of monetary asset $i$ in period $s, \mathbf{M}_{s}=\left(M_{1 \mathrm{~s}}, \ldots, M_{n s}\right)$ is the vector of nominal balances, and $\psi_{s}^{r}=\left(\psi_{1 s}^{r}, \ldots, \psi_{n s}^{r}\right)^{\prime}$ is the vector of real user costs.

Therefore, $V_{t}$ can be rewritten as follows:

$$
\begin{aligned}
V_{t} & =\sum_{s=t}^{\infty} \sum_{i=1}^{n}\left[\left(M_{i s} \frac{R_{S}-r_{i S}}{1+R_{S}}\right) \frac{1}{\rho_{S}}\right]=\sum_{s=t}^{\infty}\left[M\left(\mathbf{m}_{S}\right) \Psi\left(\Psi_{S}\right) \frac{1}{\rho_{S}}\right] \\
& =\sum_{s=t}^{\infty} \frac{(T E)_{S}}{\rho_{S}} .
\end{aligned}
$$

Note that equation (3.7) provides a connection between the Divisia aggregate flow index, $M\left(\mathbf{m}_{\mathrm{s}}\right)$, and the discounted money stock, $V_{t}$. Also observe that the formula contains a time-varying discount rate.

\subsection{CE and Simple Sum Indexes as Special Cases of the ESM}

\subsubsection{The CE Index}

Rotemberg (1991) and Rotemberg, Dricoll, and Poterba (1995) introduced the currency equivalent index (CE index),

$$
V_{t}^{C E}=\sum_{i=1}^{n}\left[\frac{\left(R_{t}-r_{i t}\right)}{R_{t}}\right] M_{i t},
$$

as a flow index under assumptions stronger than needed to derive the Divisia monetary flow index. ${ }^{13}$ But Barnett (1991b) proved that the CE index can be interpreted to be a stock index, rather than a flow index. In particular, he showed that the CE index is a special case of the ESM under the assumption of martingale expectations.

Following Barnett's proof, assume $M_{i t}, r_{i t}$, and $R_{t}$ follow martingale processes. Then equation (3.4) can be written as

\footnotetext{
${ }^{13}$ This index was earlier anticipated by Hutt (1963, p. 92, footnote).
} 


$$
V_{t}=\sum_{i=1}^{n} \sum_{s=t}^{\infty}\left[\frac{R_{t}-r_{i t}}{\left(1+R_{t}\right)^{s-t+1}}\right] M_{i t},
$$

so that

$$
V_{t}=\sum_{i=1}^{n}\left[\frac{\left(R_{t}-r_{i t}\right)}{R_{t}}\right] M_{i t}=V_{t}^{C E}
$$

This shows the CE index is a special case of the economic stock of money, when the conditional expectation of future values of variables is equal the current value.

From equation (3.9) under martingale expectations, we furthermore can show that the CE index is proportional to the Divisia current-period monetary flow aggregate, as follows:

$$
\begin{aligned}
V_{t}^{C E} & =\sum_{s=t}^{\infty} \sum_{i=1}^{n}\left[\left(\frac{R_{t}-r_{i t}}{\left(1+R_{t}\right)} M_{i t}\right) \frac{1}{\left(1+R_{t}\right)^{s-t}}\right] \\
& =\sum_{s=t}^{\infty} \frac{M\left(m_{t}\right) \Psi\left(\psi_{t}\right)}{\left(1+R_{t}\right)^{s-t}}=\sum_{s=t}^{\infty} \frac{(T E)_{t}}{\left(1+R_{t}\right)^{s-t}} .
\end{aligned}
$$

\subsubsection{The SSI Index}

We define the simple sum aggregate, $V_{t}^{S S I}$, by

$$
V_{t}^{S S I}=\sum_{i=1}^{n} M_{i t}
$$

As a flow index, this index requires that all monetary components are perfect substitutes, so that linear aggregation is possible, and furthermore that the weights in the resulting linear quantity aggregator function are equal for all components. But we also can acquire that index as a stock index under the assumption of martingale expectations, since it then follows that

$$
V_{t}^{S S I}=\sum_{i=1}^{n}\left[\frac{\left(R_{t}-r_{i t}\right)}{R_{t}}\right] M_{i t}+\sum_{i=1}^{n}\left[\frac{r_{i t}}{R_{t}}\right] M_{i t}=V^{C E}+I Y,
$$

where $I Y=\sum_{i=1}^{n}\left[\frac{r_{i t}}{R_{t}}\right] M_{i t}$ is the discounted investment yield part of the simple sum aggregate and $\mathrm{V}^{\mathrm{CE}}$ is the 
discounted monetary service flow part. ${ }^{14}$

Hence the simple sum monetary aggregate, treated as a stock index, is the stock of a joint product, consisting of a discounted monetary service flow and a discounted investment yield flow. For the SSI to be a valid as money stock measure, all monetary assets must yield no interest. Clearly investment yield cannot be viewed as a monetary service, or the entire capital stock of the country would have to be counted as part of the money stock. The simple sum monetary aggregates confound together the discounted monetary service flow and the non-monetary investment-motivated yield. The simple sum aggregates will overestimate the actual monetary stock by the amount of the discounted non-monetary services. Furthermore, the magnitude of the simple sum aggregates' upward bias will increase, as more interest-bearing monetary assets are introduced into the monetary aggregates.

Under the assumption of martingale expectations and the assumption that all monetary assets yield zero interest, it follows that:

$$
V_{t}=V_{t}^{C E}=V_{t}^{S S I}
$$

In short, the ESM is the general formula for measuring money stock and fully nests the CE and the SSI as special cases.

As deregulation of financial intermediation and financial innovation have progressed, the assumption that all monetary assets yield zero interest rates has become increasingly unrealistic.

\section{Measurement of the Economic Stock of Money}

The previous section showed that the economic monetary stock provides a general capital stock formula nesting the currency equivalent (CE) index and the simple sum index as special cases. Each of these results requires martingale expectations, and the simple sum result further requires that every monetary asset pay a nominal return of zero. This section shows how the ESM can be computed without making either of these restrictive assumptions. The earlier derivations were produced either under perfect certainty or equivalently under risk neutrality, so that random variables are implicitly replaced by their expectations. Since we now formally introduce more general expectations forecasting, we introduce the expectations

\footnotetext{
${ }^{14}$ The Divisia monetary aggregates measure the monetary service flow residual after removing the investment motive. But the simple sum aggregates, treated as a stock measure, include both the discounted monetary services flow and the discounted investment yield flow.
} 
operator, $E_{t}$, to designate expectations conditional upon all information available at current period t.

Without martingale expectations, the calculation of

$$
V_{t}=E_{t}\left[\sum_{s=t}^{\infty} \frac{(T E)_{S}}{\rho_{S}}\right]
$$

is analytically and empirically challenging. We propose three methods of approximating $\mathrm{V}_{\mathrm{t}}$. The first two linearize the function in terms of expected future variables and the third imposes a set of convenient covariance restrictions.

\subsection{Method 1: Linearizing around Current Values}

The first method uses a first-order Taylor series expansion of $V_{t}$ around current values to produce a linear approximation in the future benchmark rates, $R_{s}$, and future total monetary-services expenditures, $(T E)_{s}$. This procedure converts the non-linear expectations equation into a linear expression that is easier to evaluate. See Barnett, Chae, and Keating (2005) for the derivation of the resulting equation and details of this approach. A significant difference from either the simple sum or the CE index is that this resulting measure of $V_{t}$ depends upon past, as well as current, variables and upon coefficients in the forecasting model.

\subsection{Method 2: Martingale Expectations for Only the Benchmark Rate}

Our second method makes the martingale assumption, but only on the benchmark rate, while continuing to use VARs to forecast total monetary expenditures. This approach lies somewhere between Method 1, which uses a VAR to forecast both variables, and the CE index, which uses only current values in forecasting both variables. See Barnett, Chae, and Keating (2005) for the derivation of the resulting equation and details of this approach.

Methods 1 and 2 yield essentially the same measure of $V_{t}$, if changes in the benchmark rate are unforecastable. If, in addition, changes in total monetary expenditures are unforecastable, then the CE index, Method 1, and Method 2 all should obtain very similar measures.

\subsection{Method 3: Setting Covariances to Zero}

In general, the expected value of a nonlinear function of variables is equal to that function evaluated at the expected value of each variable plus covariance terms. Hence, the expected value of a function of variables will equal the function evaluated at the expected value of variables if and only if these covariances 
are equal to zero. Method 3 makes those simplifying assumptions. Specifically, we assume the covariance between $(T E)_{S}$ and the benchmark rate at any time is zero and all covariances between benchmark rates at different points in time are zero. See Barnett, Chae, and Keating (2005) for the derivation of the resulting equation and details of this approach.

In practice, the converged equation (4.1) must be evaluated for a finite number of periods, $\mathrm{J}$, into the future, so that:

$$
V_{t}(J)=E_{t}\left[\sum_{s=t}^{J} \frac{(T E)_{s}}{\rho_{s}}\right]
$$

This procedure requires iteration on a parameters $\mathrm{J}$. We use

$$
\left|\frac{V_{t}(J)-V_{t}(J-1)}{V_{t}(J-1)}\right|<10^{-7}
$$

as the criterion for determining the value of $\mathrm{J}$ at which to stop this iterations.

\section{Forecasting Models}

For forecasting purposes, we consider unrestricted VAR, asymmetric VAR, and Bayesian VAR which was proposed by Litterman (1986). The unrestricted vector autoregressive model (UVAR), pioneered by Sims (1980), uses historical data to summarize dynamic interaction among time series and to forecast

future values of the variables in the model. In the UVAR, each equation in the system includes the same lag length. A model with a constant and $n$ variables with $p$ lags results in $n^{2} p+n$ parameters to be estimated. The main problem with the unrestricted VAR is that the number of parameters increases very quickly with the number of variables and thus rapidly exhausts the available degree of freedom, while the number of data observation for most of macroeconomic variables is too limited to meet requirement of degree of freedom. Furthermore, because the explanatory variables are lagged values, there is high correlation among those lagged variables. This overparameterization problem, lack of degrees of freedom, and multicollinearity may lead to inefficient estimates and large out-of-sample forecast errors.

Various approaches to overcome the problems with overparameterization of UVAR have been proposed. To make large standard errors in each equation smaller, one may reduce the number of parameters by excluding insignificant lagged variables. One approach is asymmetric VAR suggested by Keating 
$(1993,2000)$. Asymmetric VAR is defined as a VAR system in which each equation contains the same explanatory variables and the lag length of each variable is the same across equations in the system, but the lag lengths of each variable may be different across the variables. Keating suggested that the AVAR produced smaller standard errors than the UVAR by permitting both flexibility in modeling and efficient estimation.

Another approach is Bayesian VAR, proposed by Litterman (1986). In BVAR, instead of entirely excluding insignificant lagged variables, we impose prior restrictions on coefficient. For each VAR model, we estimate three sub-models.

\subsection{Unrestricted VARs}

Consider the VAR system

$$
\mathbf{y}_{t}=\mathbf{c}+\mathbf{A}_{1} \mathbf{y}_{t-1}+\mathbf{A}_{2} \mathbf{y}_{t-2}+\ldots \ldots \ldots \ldots+\mathbf{A}_{p} \mathbf{y}_{t-p}+\mathbf{e}_{t}
$$

where $\mathbf{y}_{t}{ }^{\prime}=\left(\log (T E)_{t}, R_{t}, \log (I N D P R O)_{t}, \log (C P I)_{t}\right), \log (T E)_{t}$ is logged total expenditure on money services, $R_{t}$ is the benchmark asset's rate of return, $\log (I N D P R O)_{t}$ is the logged industrial production index, and $\log (C P I)_{t}$ is the logged consumer price index. In equation (5.1), $\mathbf{A}_{j}$ is a 4 by 4 matrix of parameters for $j=1, \ldots, p$, and $e_{t}$ is a four dimensional white noise vector with zero mean and constant convariance matrix.

Let $\tilde{\mathbf{y}}_{t}=\left(\mathbf{y}_{t}^{\prime}, \mathbf{y}_{t-1}^{\prime}, \ldots, \mathbf{y}_{t-p+1}^{\prime}\right)^{\prime}$. Then the system with lag length $\mathrm{p}$ can be transformed into the following VAR (1):

$$
\left[\begin{array}{c}
\mathbf{y}_{t} \\
\mathbf{y}_{t-1} \\
\cdot \\
\cdot \\
\cdot \\
\mathbf{y}_{t-p+1}
\end{array}\right]=\left[\begin{array}{c}
\mathbf{c} \\
\mathbf{0} \\
\cdot \\
\cdot \\
\cdot \\
\mathbf{0}
\end{array}\right]+\left[\begin{array}{cccccc}
\mathbf{A}_{1} & \mathbf{A}_{2} & \cdot & \cdot & \cdot & \mathbf{A}_{p} \\
\mathbf{I} & \mathbf{0} & \cdot & \cdot & \cdot & \cdot \\
\mathbf{0} & \mathbf{I} & \mathbf{0} & \cdot & \cdot & \cdot \\
\cdot & \cdot & \mathbf{I} & \cdot & \cdot & \cdot \\
\cdot & \cdot & \cdot & \cdot & \cdot & \cdot \\
\cdot & \cdot & \cdot & \cdot & \mathbf{I} & \mathbf{0}
\end{array}\right]\left[\begin{array}{c}
\mathbf{y}_{t-1} \\
\mathbf{y}_{t-2} \\
\cdot \\
\cdot \\
\cdot \\
\mathbf{y}_{t-p}
\end{array}\right]+\left[\begin{array}{c}
\mathbf{e}_{t} \\
\mathbf{0} \\
\cdot \\
\cdot \\
\cdot \\
\mathbf{0}
\end{array}\right]
$$

That is,

$\tilde{\mathbf{y}}_{t}=\tilde{\mathbf{c}}+\mathbf{A} \tilde{\mathbf{y}}_{t-1}+\mathbf{h}_{t}$, where $\mathbf{h}_{t}$ is the vector $\left(\begin{array}{llll}\mathbf{e}_{t}^{\prime} & \mathbf{0}^{\prime} \ldots \mathbf{0}^{\prime}\end{array}\right)^{\prime}, \tilde{\mathbf{c}}$ is the vector $\left(\mathbf{c}^{\prime} \mathbf{0}^{\prime} \ldots \mathbf{0}^{\prime}\right)^{\prime}$, and $\mathbf{A}$ is the 
matrix:

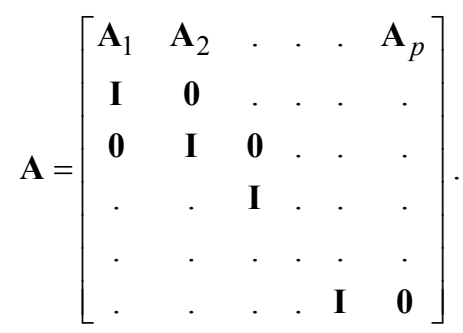

Under rational expectations, the conditional expectation results in $E_{t} \tilde{\mathbf{y}}_{t+j}=\tilde{\mathbf{c}}+\left(\sum_{i=1}^{j} \mathbf{A}^{i}\right) \tilde{\mathbf{c}}+\mathbf{A}^{j} \tilde{\mathbf{y}}_{t}$, where $\mathbf{A}^{j}$ is the matrix A raised to the power j. Clearly the j-step-ahead forecast, $E_{t} \mathbf{y}_{t+j}$, is found from the first four elements of $E_{t} \tilde{\mathbf{y}}_{t+j} \cdot{ }^{15}$

\subsection{Asymmetric VARs}

One way to reduce the number of parameters in the VAR is to eliminate the common lag assumption. Keating (1993, 2000), for example, developed the asymmetric VAR (AVAR), which is a VAR allowing lag lengths to vary across variables in the model. The AVAR and UVAR models share a common trait: each equation in the model has exactly the same set of explanatory variables. Consequently, AVARs and UVARs are consistently and efficiently estimated by ordinary least squares under standard regularity conditions. However, an AVAR model is expected to have fewer insignificant coefficients, and thereby may obtain smaller out-of-sample forecast errors than the UVAR. An AVAR lag specification can be chosen by an information criterion or by any other method capable of testing non-nested alternatives.

When considering AVAR with $\mathrm{n}$ variables and the maximum possible lag length of $p$, there are $p^{n}$ possible specifications of AVAR. The optimal lag can be chosen using information theoretic criteria.

\subsection{Bayesian VARs}

Another response to overparameterization in UVAR models is the Bayesian approach of Doan, Litterman, and Sims (1984) and Litterman (1986). A Bayesian VAR (BVAR) model avoids exclusion

\footnotetext{
${ }^{15}$ More formally, denote $\boldsymbol{\delta}_{k}^{\prime}$ to be the $4 \mathrm{p}$-dimensional vector whose elements are zero, except for the $k$-th element, which is 1 . Then the forecasted value of the $k$-th element of $\mathbf{y}_{t+j}$ can be obtained as a univariate equation from $E_{t} \tilde{\mathbf{y}}_{k, t+j}=\boldsymbol{\delta}_{k}^{\prime}\left[\tilde{\mathbf{c}}+\left(\sum_{i=1}^{j} \mathbf{A}^{i}\right) \tilde{\mathbf{c}}+\mathbf{A}^{j} \tilde{\mathbf{y}}_{t}\right]$ for $\mathrm{k}$ within the range of $\mathrm{k}=1, \ldots, 4$.
} 
restrictions, such as the different lag lengths permitted under the AVAR approach. Instead, BVAR models assume each VAR coefficient is drawn from a normal distribution and impose restrictions on the mean and the variance of each of those distributions.

We can write the $i$-th equation in a VAR as

$$
\begin{aligned}
y_{i t}= & c_{i}+\phi_{i 1}^{(1)} y_{1, t-1}+\phi_{i 2}^{(1)} y_{2, t-1}+\cdots+\phi_{i n}^{(1)} y_{n, t-1} \\
& +\phi_{i 1}^{(2)} y_{1, t-2}+\phi_{i 2}^{(2)} y_{2, t-2}+\cdots+\phi_{i n}^{(2)} y_{n, t-2}+\cdots \\
& +\phi_{i 1}^{(p)} y_{1, t-p}+\phi_{i 2}^{(p)} y_{2, t-p}+\cdots+\phi_{i n}^{(p)} y_{n, t-p}+\varepsilon_{i t}
\end{aligned}
$$

where $\phi_{i j}^{(l)}$ is the coefficient on lag $l$ of variable $j$ in equation $i$.

Litterman's (Minnesota) prior is consistent with the observation that most economic variables can be approximated by a random-walk with drift. If that case were exactly true, equation (5.2) would take the following form:

$$
y_{i t}=c_{i}+y_{1, t-1}+\varepsilon_{i t}
$$

The Minnesota (or Litterman) prior appeals to the empirical evidence that most economic variables appear to have a unit root. Thus each coefficient is given a prior mean of zero, except for the coefficient on the first lag of the dependent variable in each equation. That coefficient has a mean of one. Coefficients on shorter lags are given larger prior variances than the coefficients on longer lags. This choice of prior variances is based on the reasonable assumption that recent data are likely to be more informative than older data in explaining current outcomes, so that data should be permitted to dominate prior views regarding short lag parameters. This approach also allows different priors to be imposed on different variables. For example, if a certain variable is thought to have more explanatory power than other variables, the prior variance associated with that variable would be made larger than that for the other variables, to permit the information in the data to dominate the prior. Flat (non-informative) priors are assumed for all deterministic variables.

The standard deviation on the coefficient estimate for lag $l$ of variable $j$ in equation $i$ in the VAR is specified as follows:

$$
S(i, j, l)=\frac{[\gamma g(l) w(i, j)] s_{i}}{s_{j}}
$$


where $w(i, j)=\left\{\begin{array}{l}1, \text { if } i=j \\ w_{i j}, \text { otherwise, }\end{array}\right.$

$g(l)=l^{-d}$,

$\gamma=$ standard deviation on the first own lag coefficient,

$s_{i}=$ the standard error of a univariate autoregression for variable $i$,

$d=$ lag decay parameter,

$w(i, j)=$ relative tightness on variable $j$ in equation $i$ relative to that of variable $i$.

Litterman scaled the standard error on the prior by the ratio, $s_{i} / s_{j}$, to correct for differences in the unit of measurement of variable $j$ relative to variable $i$. The standard deviation, $\gamma$, on the first own lag determines the overall tightness of the priors. Smaller $\gamma$ means that we are more confident in our prior that the coefficient on the first own lag, $\phi_{i i}^{(1)}$, is close to unity, while $w(i, j)$ determines the tightness of the prior on variable $j$ relative to variable $i$ in equation $i$ and reflects the importance of variable $j$ relative to $i$ in equation $i$. The smaller the value of $w(i, j)$ the tighter the prior and the less the implied interaction between variables $i$ and $j$. If the analyst has a strong belief that one variable is exogenous to another variable, assigning more weight can improve forecasting performance. The setting of $g(l)$ controls the tightness on the first lag relative to the $l$-th lag, and $g(l)$ is assumed to decrease with decay factor $d$. Hence, the tightness on the prior for long lags will increase by imposing larger decay factor $d .{ }^{16}$

The prior distributions on each parameter can be summarized as follows:

$$
\begin{aligned}
& \phi_{i i}^{(1)} \sim N\left(1, \gamma^{2}\right), \\
& \phi_{i i}^{(l)} \sim N\left(0, \gamma^{2} g^{2}(l)\right) \text { for } l=2,3,4, \ldots, p, \\
& \phi_{i j}^{(l)} \sim N\left(0, \frac{[\gamma g(l) w(i, j)]^{2} s_{i}^{2}}{s_{j}^{2}}\right) \text { for } j \neq i \text { and } l=1,2, \ldots, p .
\end{aligned}
$$

\footnotetext{
${ }^{16}$ If $d=1$, then $g(1)=1, g(2)=0.5, g(3)=0.33, g(4)=0.25, \ldots$
} 
The BVAR model can be estimated using Theil's (1971) mixed-estimation technique. The mixed-estimation technique incorporates prior information on the distributions of the coefficients with information obtained from data.

\section{Model Specification}

\subsection{Data Description}

The models in this paper use U.S. data for total user-cost-evaluated expenditure on monetary services $(T E)$, the benchmark interest rate $(B E N C H)$, industrial production (INDPRO), and the consumer price index $(C P I)$. Relative to the notation in section (2.1), $B E N C H_{t}=R_{t}$ and $C P I_{t}=p_{t}{ }^{*}$, although the latter equality is an index number theoretic approximation to the exact true cost of living index of economic theory. Data are monthly and seasonally adjusted, covering the period from 1959:1 through 2004:3. All data were obtained from the Federal Reserve Economic Database (FRED), published by the Federal Reserve Bank of St. Louis. ${ }^{17}$ The initial choice of output and price was based on a priori beliefs regarding those variables most likely to help forecast interest rates and monetary-services expenditures. Those prior beliefs were then supported by statistical tests for marginal predictive content. We also considered other variables in the specification search, but those additional variables did not improve the forecasts and are therefore omitted from the final equations. The list of monetary assets used in computing each level of the monetary aggregates are reported in table 16 in the appendix.

The choice of benchmark rate can have important consequences for the economic stock of money or the currency equivalent index. Rotemberg, Driscoll and Poterba (1995) used the commercial paper rate and found that their $\mathrm{CE}$ index was extremely volatile. Our benchmark rate path is the upper envelope over the paths of Moody's BAA bond rate and all the interest rates that go into the calculation of ESM, as in Anderson,

\footnotetext{
${ }^{17}$ At each level of aggregation, $\mathrm{j}$, total expenditure on the monetary services, $(T E)_{t}^{j}$, was computed from the first equality in equation (3.6). Hence TE is not an index number, but computed from an accounting identity with user cost prices. But the second equality in equation (3.6) is Fisher's factor reversal assuring that the nominal expenditure produced from the Divisia monetary aggregate must equal this sum of expenditures on component services. In discrete time, there is a small third order error in the second equality, when using the Törnqvist approximation to the continuous time Divisia index.
} 
Jones, and Nesmith $(1997 \mathrm{a}, \mathrm{b}) .{ }^{18}$ The resulting benchmark rate is not as volatile as the commercial paper rate.

In each VAR, we control for the effects of exogenous oil supply shocks by including dummy variables for oil shock dates. We used the dates identified by Hoover and Perez (1994). ${ }^{19}$ To model the dynamic response of the economy to oil price shocks, the VAR included current and seven lags of the oil shock dummy variables.

\subsection{Nonstationarity and Data Transformation}

Specification of VAR models for forecasting requires consideration of several important issues: (i) tests for stationarity of time series, (ii) consideration of variables included in the VAR, (iii) selection of lag length, and (iv) specification of prior structure and hyperparameters, in the BVAR case. The model needed to test the null hypothesis of a stochastic trend against the alternative of a deterministic trend is

$$
\Delta y_{t}=\eta+\omega t+\xi y_{t-1}+\sum_{i=1}^{p-1} \xi_{i} \Delta y_{t-i}+u_{t}, \text { where } u_{t} \sim \operatorname{IID}\left(0, \sigma^{2}\right) .
$$

Table 1 in Barnett, Chae, and Keating (2005) reports the results from the augmented Dickey-Fuller and Phillips-Perron (PP) Z-tests on the three stochastic processes: $B E N C H_{t}, \log C P I_{t}$, and $\log I N D P R O_{t}$. A unit root is found in each test with each variable. Therefore, UVAR and AVAR are estimated in the first differences of each of those three processes. Because the benchmark rate is an interest rate, those levels and changes were not transformed by logarithm in any of the models.

The BVAR models are estimated in the log levels, since our prior assumptions allow for possible unit roots. In fact in general, Sims et al. (1990) have shown that BVAR can be specified in levels, even when

\footnotetext{
${ }^{18}$ Direct measurement of the theoretical benchmark rate is not possible, since in theory the benchmark cannot have a secondary market. This approach to producing a proxy for the benchmark rate of return is not consistent with the more recently proposed approach of Barnett (2005). But since the benchmark rate appears symmetrically in all terms of the numerator and denominator of the shares, the weights of the Divisia index are far more robust to errors in the benchmark rate than to errors in the own rates of return of monetary assets. The primary problem to be avoided in producing a proxy to the benchark rate is negative user costs that can result from adopting a benchmark rate that can be less than an own rate of return on a monetary asset. The incorporation of a Baa bond rate within the envelope produces problems regarding term structure theory and the treatment of risk, but is consistent with the findings of Shiller (1979), whose work influenced the Federal Reserve's decision to introduce a bond rate into the envelope.

${ }^{19}$ Hoover and Perez's (1994) shock dates are 1969:3, 1970:12, 1974:1, 1978:3, 1979:9 and 1981:2.
} 
variables contain a unit root. The dependency of the Bayesian approach on the likelihood function is not affected by the existence of a unit root.

\subsection{Selection of Lag Length}

The selection of the order of the VAR is an important step in the choice of the specification. To choose optimal lag lengths of the unrestricted VAR and Bayesian VAR, we used the likelihood ratio test statistic (LR), suggested by Sims(1980). The LR test statistic for restrictions imposed on a general VAR model is: $(\mathrm{T}-\mathrm{k})\left[\left[\log \left|\sum_{r}\right|-\log \left|\sum_{u n r}\right|\right]\right.$ where $\mathrm{T}$ is the sample size, $\mathrm{k}$ is the number of parameters estimated in each equation of the VAR, $\log \left|\sum_{r}\right|$ is the log determinant of the variance-covariance matrix of the residuals in the fitted restricted model, and $\log \left|\sum_{u n r}\right|$ is the log determinant of the variance-covariance matrix of the residuals in the fitted unrestricted model. The statistic has a $\chi^{2}$ distribution with degree of freedom equal to the number of restrictions imposed. The term, T-k, includes a small-sample degrees-of-freedom correction, $\mathrm{k}$, and as $\mathrm{T}$ becomes larger the correction for a small sample (T-k)/T converges towards unity. For LR tests, we consider a maximum lag of $\mathrm{m}=24^{20}$ and test $\mathrm{m}$ against $\mathrm{m}-1$ sequentially downwards, until the first significant LR statistic at the 1 percent level is found. The LR test results in the selection of 13 lags.

To select the lag length of AVAR, we used Akaike's information criterion (AIC) and Schwarz's information criterion (SIC). In the AVAR, we limited consideration to a maximum of 13 lags for each variable, to avoid the extreme computational time that would have been required to select optimal lags by those methods. For 4 variables and up to 13 lags, there are $13^{4}$ possible AVAR specifications. For the AVAR-M1 model at the M1 level of aggregation, the AIC chose six lags of $\Delta \log (T E)^{m 1}$, three lag of $\triangle \log I N D P R O$, six lags of $\triangle \log C P I$, and six lags of $\triangle B E N C H$, while for the AVAR-M2 model at the M2 level of aggregation and the AVAR-M3 model at the M3 level of aggregation, AIC selected six lags of $\Delta \log (T E)^{m 2}$ in the AVAR-M2 model, six lags of $\Delta \log (T E)^{m 3}$ in the AVAR-M3 model, three lags of $\triangle \log I N D P R O$, six lags of $\triangle \log C P I$, and seven lags of $\triangle B E N C H$. On the other hand, the SIC chose

\footnotetext{
${ }^{20}$ With monthly data used for the analysis, we consider a maximum of 24 months for lags.
} 
only 1 or 2 lags in all variables. Considering that the data used is monthly, we view the SIC lag lengths to be too short to capture dynamics of series in a credible manner. For this reason, we estimated the AVAR models with lags chosen by the AIC criterion.

To select variables to be included in our forecasting models, we conducted block Granger-causality tests to examine whether lagged values of a variable help to forecast the benchmark rate and total expenditure on monetary services. The results are reported in table 1 . The lagged values of $\log C P I$ and $\log I N D P R O$ contribute to forecasting expenditure on monetary services and the benchmark rate. 
Table 1. Block Exogeneity Test

\begin{tabular}{|l|l|l|}
\hline & $\log \mathrm{TE}$ and Bench in Levels & $\Delta \log \mathrm{TE}$ and $\triangle \mathrm{Bench}$ \\
\hline lag length & 13 & 13 \\
\hline Log CPI & 0.00461 & 0.00956 \\
\hline Log INDPRO & 0.04475 & 0.00239 \\
\hline
\end{tabular}

Note: The entries in the last two rows of the table are significance levels (P-values or tail areas of tests) based on the likelihood ratio test.

\subsection{Criterion for Evaluation of Forecasting Performance}

Forecasts are assessed using the following procedure. Estimate a VAR with the sample from 1959:1 to 1990:12 and forecast for each month up to 48 months ahead. Then add the next month's data to the sample, estimate a VAR, and forecast up to 48 periods ahead. Continue adding a month, re-estimating the VAR, and forecasting until there is no actual data available to be compared with forecasts. Since our full sample ends in 2004:3, our sequential procedure stops at 2004:3.

Then we use root mean squared error (RMSE) and Theil's $U$ statistic to evaluate forecasting models. If $y_{t+h}$ is the value of a variable at $\mathrm{t}+\mathrm{h}$ and $\hat{y}_{t+h}$ is the forecast of this variable at time $\mathrm{t}$, then

$$
R M S E(\text { model })=\sqrt{T^{-1} \sum_{t=1}^{T}\left(y_{t+h}-\hat{y}_{t+h}\right)^{2}}
$$

and

$$
\text { Theil } U=\frac{\text { RMSE (model) }}{\text { RMSE (random walk) }}=\sqrt{\frac{\sum_{t=1}^{T}\left(y_{t+h}-\hat{y}_{t+h}\right)^{2}}{\sum_{t=1}^{T}\left(y_{t+h}-y_{t}\right)^{2}}} \text {, }
$$

where $h$ is the forecast horizon and $T$ is the total number of forecasts computed for the forecast horizon $h$. Theil's $U$ statistic compares the RMSE for a model's forecast errors with the RMSE from a no-change forecast. When a $U$ statistic is less than one, the model forecasts better than a no-change forecast. If a $U$ statistic exceeds one, the naive no-change forecast outperforms the model. Note that a no-change forecast is analogous to the martingale expectations assumption used by Barnett (1991b) to motivate the CE index as a 
stock index. Thus when U-statistics are less than 1, our approximations are expected to be more accurate measures of the ESM than the CE index.

\subsection{Specification of Priors}

In estimating the BVAR, the first step is to search for the hyperparameters of the Litterman (1986) prior, $\gamma, d$, and $\mathbf{W}$, that can minimize out-of-sample forecast errors. The criterion function, $\bar{U}$, used in selecting the priors is set to be the weighted average of the Theil $U$ statistics for one month-ahead to 24 months-ahead forecasts. The weights are the number of forecasts for each forecast horizon divided by the total number of forecasts for all forecast horizons during a given period. The hyperparameters are $\gamma=$ measure of overall tightness, $d=$ the lag decay parameter, and $\mathbf{W}=\left[w_{i j}\right]$, where $w_{i j}=$ relative tightness, defined to be the tightness on variable $j$ in equation $i$ relative to variable $i$. In the literature on this BVAR approach, the parameter $\gamma$ is usually equal to the standard deviation of the parameter of the first own lag in each equation in the VAR. The parameters $\gamma$ and $d$ are scalars that are constant across equations in the specification. For more formal definitions of parameters and details of the BVAR specification, see sections 5.3 above. $^{21}$

After many experiments, we decided to estimate two sets of priors by minimizing the criterion function over two different periods (1989:1-1990:12, 2000:1-2001:12). With starting periods in the range 1991:1 to 2001:12 and 2002:1 to 2004:3, respectively, we applied the priors in generating forecasts for up to 200 steps ahead. $^{22}$ The reason we select two sets of priors for two different periods is that the best priors selected on the basis of a certain period may not necessarily be optimal for far beyond that period. Forecast performance is sensitive to the priors. The priors were selected by searching over the arguments $(\gamma, \mathbf{W}, d)$ to minimize the following objective function:

$$
\operatorname{Min} \bar{U}(\gamma, \mathbf{W}, d)=\sum_{i=1}^{2} \sum_{h=1}^{24} \alpha_{h} U_{i h}=\sum_{i=1}^{2} \bar{U}_{i},
$$

where the $i=1,2$ subscript indexes the two variables, total monetary-services expenditure and benchmark

\footnotetext{
${ }^{21}$ Alternatively see Littermann (1986) regarding the "Litterman prior."

${ }^{22}$ Although we do not consider more than 48 step-ahead forecasts to be meaningful in comparing models, we needed more than 48 step-ahead forecasts to seek convergenece of equation (4.2). We generated the 200 step ahead forecasts to assure that we would have enough to attain convergence of
} 
rate, $h$ is forecast step, $U_{i h}$ is Theil's $\mathrm{U}$ statistic for variable $i$ 's $h$-step ahead forecast, $\alpha_{h}=\frac{k_{h}}{K}$ is the weight for each forecast step $h$, and $\bar{U}_{i}=\sum_{h=1}^{24} \alpha_{h} U_{i h}$ is the weighted average of Theil's $U$ statistics for variable $i$ 's 1 -month-ahead to 24 -months-ahead forecasts during the evaluation period. ${ }^{23}$ The variable $\mathrm{k}_{\mathrm{h}}$ is the number of times that the $h$-step ahead forecast has been computed during the evaluation period, and $K=\sum_{h=1}^{24} k_{h}$ is the total number of times that all forecasts for 1 to 24 months ahead have been computed during the evaluation period. ${ }^{24}$

The criterion function (6.2) is an average of the accumulated Theil $U$ statistics for all forecasts during the evaluation period. The number of forecasts, $k_{h}$, at each forecast-step decreases, as the forecast steps become longer during the evaluation period. Hence, the number of forecast statistics for shorter-step horizons, relative to that of all step-horizons, plays a role as a weight, in computing average Theil $U$ statistics for all forecast step horizons in the criterion function. In constructing the criterion function, more weight is thereby put on shorter forecast steps than longer ones. Forecasts of total monetary-services expenditure and of the benchmark rate will enter the formula for the discounted economic money stock. As expected from the flow discounting, the weight on shorter forecast steps will be heavier than on longer ones, since forecasts for short horizons will have the heaviest impact in determining the discounted economic stock of money.

As observed above, more weight is put on shorter forecast steps than longer ones in computing the criterion function, since $k_{h}$ decreases naturally as the forecast horizon becomes longer for a given evaluation period. In particular, using our VAR notation, we also can show that 1-step error gets additional weight relative to the 2-step error, the 2-step error more weight than the 3-step error, etc. Define VAR(p) by

(4.10). But for purposes of evaluating forecast performance, we used no more than 48 step-ahead forecasts.

${ }^{23}$ In principle, there could be advantages to selecting an objective function that is directly derivable from the ESM formula. But in choosing equation (6.2), we had the more modest objective of minimizing forecast errors. Regarding the limitation to 24 step-ahead forecasts for this purpose, we would have preferred to have used 48 step-ahead forecasts, but data limitations prevented us from doing so. We forecasted 1989:1 - 1990:12, after using data up to 1988:12 to estimate the priors. The split of the sample between observations needed for estimating the priors and observations used in forecast evaluation prevented forecast evaluation for 48 step-ahead forecasts. If we had split the sample earlier, there would not have been enough observations available for the estimation of priors. 


$$
\mathrm{B}(\mathrm{L}) \mathbf{y}_{\mathrm{t}}=\mathbf{e}_{\mathrm{t}} \text {, where } \mathrm{B}(\mathrm{L})=\mathrm{I}-\mathbf{A}_{1} \mathrm{~L}-\mathbf{A}_{2} \mathrm{~L}^{2}-\mathbf{A}_{3} \mathrm{~L}^{3} \ldots \ldots \ldots-\mathbf{A}_{\mathrm{p}} \mathrm{L}^{\mathrm{p}} \text {. }
$$

Then for any $\operatorname{VAR}(\mathrm{p})$, we have:

$\mathbf{y}_{t}=\mathbf{A}_{1} \mathbf{y}_{t-1}+\mathbf{A}_{2} \mathbf{y}_{t-2}+\ldots .+\mathbf{A}_{p} \mathbf{y}_{t-p}+\mathbf{e}_{t}$

so that

$\mathbf{y}_{t+1}=\mathbf{A}_{1} \mathbf{y}_{t}+\mathbf{A}_{2} \mathbf{y}_{t-1}+\ldots .+\mathbf{A}_{p} \mathbf{y}_{t-p+1}+\mathbf{e}_{t+1}$

and hence

$E_{t} \mathbf{y}_{t+1}=\mathbf{A}_{1} \mathbf{y}_{t}+\mathbf{A}_{2} \mathbf{y}_{t-1}+\ldots .+\mathbf{A}_{p} \mathbf{y}_{t-p+1}$.

It follows that the 1-step-ahead forecast error is $\mathbf{e}_{t+1}$, the 2- step-ahead forecast error is

$\mathbf{e}_{t+2}+\mathbf{A}_{1} \mathbf{e}_{t+1}$, and hence the h-step forecast error is

$$
\mathbf{y}_{t+h}-E_{t} \mathbf{y}_{t+h}=\sum_{i=0}^{h-1} \mathbf{A}_{i} \mathbf{e}_{t+h-i}
$$

From equation (6.3), we can see that 1 -step error at time $\mathrm{t}+1$ appears in the formula for all $\mathrm{h}$. For instance, if the initial estimate goes through 1988:12 and the evaluation period is 1989:1 to 1990:12, then the number of one-step-ahead forecasts will be 24 , the number of two-step ahead forecasts will be 23 , and so on. Hence, forecast errors for short horizon are given more weight than forecast errors for longer horizons.

Recall that the forecasts of the benchmark rate and total expenditure on monetary services will enter the formula for the economic money stock present value. So we should expect that short horizon forecasts of the benchmark rate and total monetary services will have more weight in determining the economic stock of money than long horizon forecasts.

Our criterion function includes $U$ statistics for only total monetary-services expenditure and the benchmark rate, instead of considering all variables in the VAR, since we are forecasting only those two variables. As shown below equation (5.4), we normalize the diagonal elements of $\mathbf{W}$ to equal 1.0, so w(i,i) $=$ 1.0 for all $\mathrm{i}$ in all cases of BVAR. We start with a symmetric prior by setting the same value, $\mathrm{w}$, for relative tightness, $w_{i j}$, to all the off-diagonal variables of $\mathbf{W}$, and then relax the prior to allow for more general interactions among the variables. The search for the optimizing hyperparameters was conducted using the

\footnotetext{
${ }^{24}$ For instance, when $h=1,2, \ldots, 24$, and if evaluation period is 24 months, then $k_{l}$ is $24, k_{2}$ is $23, \ldots$. ,
} 
genetic algorithm optimization method.

For notational convenience, we will name the models according to the level of aggregation: UVAR-M1, UVAR-M2, and UVAR-M3 are unrestricted VAR models, with the total expenditure variable being on the services of the monetary assets that are included in M1, M2 and M3, respectively. Analogously AVAR-M1, AVAR-M2, and AVAR-M3 are the asymmetric VAR model, with the total expenditure variable being on the services of monetary assets that are included in M1, M2 and M3, respectively; while BVAR-M1, BVAR-M2, and BVAR-M3 are the Bayesian VAR model, with total expenditure being on the services of monetary assets that are included in M1, M2 and M3, respectively.

When we searched for symmetric priors by minimizing the criterion function over two different periods (1989:1-1990:12, 2000:1-2001:12), we found no symmetric prior that produced average $U$ statistics for the benchmark rate that were less than one in all three BVAR models for the period 1989:1-1990:12. Hence, we then searched for general priors to optimize the criterion function. For total monetary-services expenditure and for the benchmark rate, the best general priors yield Theil $U$ statistics that are less than one for all models. Tables 2 and 3 of Barnett, Chae, and Keating (2005) show how much the average of Theil's $U$ statistics, under the general prior specification, have improved, compared to that under the symmetric prior. In those tables, "Average $U$ " means $\bar{U}_{i}$ with $i=1$ for total expenditure and $\mathrm{i}=2$ for benchmark rate.

Table 2, 3, 4, and 5 provide the hyperparameter estimates. The resulting average Theil $\mathrm{U}$ statistic in each case is provided in Barnett, Chae, and Keating (2005). They demonstrated that with symmetric priors there is no way to produce benchmark rate average $\mathrm{U}$ statistics that are less than one in all three BVAR models. Under general priors, Barnett, Chae, and Keating (2005) showed that Theil's U statistics for the benchmark rate and total monetary services expenditure are less than one for all models. However, many elements in the off-diagonal are close to zero. As a result, the BVAR model approaches a univariate autoregression of each variable on its own lags. In this case, there may be little gain from using a multivariate model.

and $k_{24}$ is 1 . 
Table 2. BVAR Hyperparameters with Symmetric Priors

\begin{tabular}{|c|c|c|c|}
\hline \multicolumn{4}{|l|}{ BVAR-M1 Model } \\
\hline $\begin{array}{l}\text { Period for } \\
\operatorname{Min}(\bar{U})\end{array}$ & $\gamma$ & $\mathrm{W}$ & $d$ \\
\hline 1989:1-1990:12 & 0.001 & 0.0001 & 2.99 \\
\hline 2000:1-2001:12 & 0.002656 & 0.0923 & 2.99 \\
\hline \multicolumn{4}{|l|}{ BVAR-M2 Model } \\
\hline $\begin{array}{l}\text { Period for } \\
\operatorname{Min}(\bar{U})\end{array}$ & $\gamma$ & $\mathrm{w}$ & $d$ \\
\hline 1989:1-1990:12 & 0.001 & 0.0001 & 2.99 \\
\hline 2000:1-2001:12 & 0.001 & 0.103 & 2.99 \\
\hline \multicolumn{4}{|l|}{ BVAR-M3 Model } \\
\hline $\begin{array}{l}\text { Period for } \\
\operatorname{Min}(\bar{U})\end{array}$ & $\gamma$ & $\mathrm{W}$ & d \\
\hline 1989:1-1990:12 & 0.001 & 0.0001 & 2.99 \\
\hline $2000: 1-2001: 12$ & 0.001 & 0.108 & 2.99 \\
\hline
\end{tabular}

Note: With symmetric prior, $\mathrm{w}$ is defined to be the common off-diagonal element of $\mathbf{W}$, and therefore $\mathrm{w}$ is a scalar in this case.

Table 3. BVAR-M1Hyperparameters with General Priors

\begin{tabular}{|l|l|l|l|}
\hline $\begin{array}{l}\text { Period for } \\
\operatorname{Min}(\bar{U})\end{array}$ & $\gamma$ & $\mathbf{W}$ & $d$ \\
\hline $1989: 1-1990: 12$ & 0.13 & $\mathbf{W}_{1}^{m 1}$ & 2.31 \\
\hline $2000: 1-2001: 12$ & 0.0045 & $\mathbf{W}_{2}^{m 1}$ & 1.62 \\
\hline
\end{tabular}

where 


$$
\mathbf{W}_{1}^{m 1}=\left[\begin{array}{ccccc} 
& (T E)^{m 1} & \text { INDPRO } & \text { CPI } & \text { BENCH } \\
(T E)^{m 1} & 1.0 & 0.001 & 0.0059 & .0001 \\
\text { INDPRO } & 0.867 & 1.0 & 0.013 & 0.0097 \\
C P I & 0.0002 & 0.0001 & 1.0 & 0.69 \\
B E N C H & 0.0001 & 0.0001 & 0.0015 & 1.0
\end{array}\right]
$$

and

$$
\mathbf{W}_{2}^{m 1}=\left[\begin{array}{ccccc} 
& (T E)^{m 1} & \text { INDPRO } & \text { CPI } & \text { BENCH } \\
(T E)^{m 1} & 1.0 & 0.0001 & 0.0001 & 0.748 \\
I N D P R O & 0.544 & 1.00 & 0.176 & 0.964 \\
C P I & 0.204 & 0.046 & 1.0 & 0.359 \\
B E N C H & 0.999 & 0.0001 & 0.0001 & 1.0
\end{array}\right] .
$$

Table 4. BVAR-M2 Hyperparameters with General Priors

\begin{tabular}{|l|l|l|l|}
\hline $\begin{array}{l}\text { Period for } \\
\operatorname{Min}(\bar{U})\end{array}$ & $\gamma$ & W & $d$ \\
\hline $1989: 1-1990: 12$ & 0.065 & $\mathbf{W}_{1}^{m 2}$ & 1.93 \\
\hline $2000: 1-2001: 12$ & 0.0038 & $\mathbf{W}_{2}^{m 2}$ & 0.98 \\
\hline
\end{tabular}

where

$$
\mathbf{W}_{1}^{m 2}=\left[\begin{array}{ccccc} 
& (T E)^{m 2} & I N D P R O & C P I & B E N C H \\
(T E)^{m 2} & 1.0 & 0.073 & 0.005 & 0.0014 \\
I N D P R O & 0.009 & 1.0 & 0.008 & 0.002 \\
C P I & 0.047 & 0.124 & 1.0 & 0.643 \\
B E N C H & 0.0007 & 0.0006 & 0.003 & 1.0
\end{array}\right]
$$

and

$$
\mathbf{W}_{2}^{m 2}=\left[\begin{array}{ccccc} 
& (T E)^{m 2} & \text { INDPRO } & C P I & \text { BENCH } \\
(T E)^{m 2} & 1.0 & 0.999 & 0.0001 & 1.0 \\
\text { INDPRO } & 1.0 & 1.0 & 0.184 & 0.999 \\
C P I & 0.006 & 0.999 & 1.0 & 0.003 \\
B E N C H & 1.0 & 0.0001 & 0.0001 & 1.0
\end{array}\right] .
$$


Table 5. BVAR-M3 Hyperparameters with General Priors

\begin{tabular}{|l|l|l|l|}
\hline Period for & \multicolumn{1}{|c|}{$\gamma$} & W & $d$ \\
\hline 1989:1-1990:12 & 0.075 & $\mathbf{W}_{1}^{m 3}$ & 2.02 \\
\hline $2000: 1-2001: 12$ & 0.00264 & $\mathbf{W}_{2}^{m 3}$ & 0.3 \\
\hline
\end{tabular}

where

$$
\mathbf{W}_{1}^{m 3}=\left[\begin{array}{ccccc} 
& (T E)^{m 3} & \text { INDPRO } & \text { CPI } & \text { BENCH } \\
(T E)^{m 3} & 1.0 & 0.082 & 0.0002 & 0.0096 \\
\text { INDPRO } & 0.029 & 1.0 & 0.068 & 0.0074 \\
C P I & 0.24 & 0.49 & 1.0 & 0.16 \\
B E N C H & 0.0017 & 0.0002 & 0.0026 & 1.0
\end{array}\right]
$$

and

$$
\mathbf{W}_{2}^{m 3}=\left[\begin{array}{ccccc} 
& (T E)^{m 3} & I N D P R O & C P I & B E N C H \\
(T E)^{m 3} & 1.0 & 1.0 & 0.36 & 1.0 \\
I N D P R O & 0.999 & 1.0 & 0.0001 & 0.999 \\
C P I & 0.999 & 0.0004 & 0.999 & 1.0 \\
B E N C H & 0.999 & 0.0001 & 0.0001 & 1.0
\end{array}\right] .
$$

\section{Empirical Results: Forecasting Performance and Evaluation}

The accuracy of out-of-sample forecasts for 1991:1-2004:3 was evaluated based on the average of Theil's U statistics for 1 to 48 month ahead forecasts. Before generating out-of-sample forecasts, we selected the optimal lag length to be 13 lags for each variable in the UVAR models, based on LR tests, and we used the same lag length for BVAR models.

The procedures for evaluating forecasting performance are as follows. First, models are recursively estimated using initial data from 1959:1 to 1990:12, and then 1 to 48 month-ahead forecasts are computed by iterating the reduced form of the VAR models forward. Theil's $U$ statistics are computed from those forecasts 
and the observed data. Next, each model is re-estimated using data with one additional observation (1959:1-1991:1). Then 1 to 48 month-ahead forecasts are again computed, and the corresponding Theil's U statistics are computed. This procedure is repeatedly conducted through 2004:3.

Forecasting performance of BVAR cannot be compared directly with those of UVAR and AVAR, because the BVAR model is estimated in log level, while the UVAR and AVAR modesl are estimated in log difference. Barnett, Chae, and Keating (2005) report UVAR and AVAR out-of-sample forecast performance statistics, based on the average of Theil's U statistics for 1 to 48 step-ahead forecast errors over the period 1991:1 to 2004:3. To avoid poor generalization about forecasting performance across sample period, the results are also reported for sub-samples 1991:1-1995:12, 1996:1-2001:12, and 2002:1-2004:3. Barnett, Chae, and Keating (2005) report those results, since forecasting performance may depend upon sample period. In all three AVARs (AVAR-M1, AVAR-M2, AVAR-M3) and all three UVARs (UVAR-M1, UVAR-M2, UVAR-M3), the averages of Theil U statistics for $(T E)^{m 1},(T E)^{m 2},(T E)^{m 3}$, and the benchmark rate are significantly less than one, over the full sample periods and the sub-sample periods. Hence, forecasts of total expenditure and benchmark rate based on AVARs and UVARs are more accurate than martingale forecasts assuming no change in the TES and benchmark rate from their current values.

Comparing performances of AVARs relative to those of UVARs in forecasting benchmark rate, with average Theil statistics of 0.737 for AVAR-M1, 0.738 for AVAR-M2, and 0.738 for AVAR-M3, Barnett, Chae, and Keating (2005) find that AVARs perform slightly better than the UVARs counterparts over all sample periods except for the third sub-period 2002:1-2004:3, during which UVAR-M1 and UVAR-M2 outperform the AVAR counterparts. In addition, Barnett, Chae, and Keating (2005) find that the average Theil's $U$ statistics for $(T E)^{m 1},(T E)^{m 2}$, and $(T E)^{m 3}$ from AVARs are also less than those from UVARs over most of the sample periods, but are only marginally less.

To examine forecasting performance for various forecasting horizons, we compute in this paper the average Theil's $U$ statistics for every additional 6 month horizon. The results below indicate that over short horizons, AVAR-M models improve relative to the UVAR-M models. In addition, in both AVARs and UVARs, the average Theil's $U$ statistics over the shorter horizons are greater than those over the longer horizons, so that forecasting accuracy of AVARs and UVARs improves relative to random walk forecasting 
model over the longer horizons.

We also report in-sample forecast statistics over 1960:2-1990:12 in tables 11, 12, 13, and 14 below. In contrast with out-of-sample forecast performance, the in-sample forecast statistics show that UVARs marginally outperform AVARs in terms of average Theil's U statistics for $(T E)^{m 1},(T E)^{m 2}$, and $(T E)^{m 3}$, and the benchmark rate, especially over short forecasting horizons; while over longer horizon, there is hardly any difference between UVARs and AVARs. In addition, within-sample forecasting accuracy of both UVARs and AVARs improves over the shorter horizons.

Barnett, Chae, and Keating (2005) report forecast performance for the BVAR model. They estimate BVARs by using two sets of general priors for two different periods, 1991:1-2001:12 and 2002:-2004:3, respectively, since the accuracy of the forecasts is sensitive to the specification of the priors and the optimal prior is likely to depend on sample period. The set of priors obtained by minimizing the weighted average of U values for 1989:1 to 1990:12 was used to generate forecasts for the period of 1991:1 to 2001:12, and the other set of priors obtained from 2000:1 to 2001:12 was applied to compute forecasts for the period of 2002:1 to $2004: 3^{25}$.

Over the sample period 1991:1 to 2001:12, forecasts of $(T E)^{m 1},(T E)^{m 2}$, and $(T E)^{m 3}$ in Barnett, Chae, and Keating (2005) from BVARs are better than the corresponding no-change forecasts. But forecast performances for $(T E)^{m 1}$ and $(T E)^{m 2}$ are unimpressive in that paper, since the average $U$ statistics are not considerably less than one. Over the period 2002:1 to 2004:3, forecasts of TEs from the BVAR models are even worse than the no-change forecasts, with average $U$ statistics of $1.28,1.19$, and 1.29 for $(T E)^{m 1}$, $(T E)^{m 2}$, and $(T E)^{m 3}$, respectively. On the other hand, out-of sample forecasts of the benchmark rate from BVAR-M1, BVAR-M2, and BVAR-M3 are consistently and substantially better than the no-change forecast in all sample periods.

\footnotetext{
${ }^{25}$ The time frame is as follows: 1959:1-1988:12: Initial estimation 1989:1-1990:12: Specify a set of priors by minimizing criterion function over this period. 1991:1-2001:12: Generate forecasts and evaluate out-of-sample forecast performance. 2000:1-2001:12: Specify a set of priors by minimizing criterion function over this period.
} 
In Table 9 we now report average Theil' U statistics from BVARs for various forecasting horizons. That table shows that the BVARs outperform the naive martingale model for TEs and benchmark rate over long horizons, while, at relatively shorter horizons, forecasts of TEs and the benchmark rate from BVARs are only marginally better than from the naive model.

Looking at table 15 that shows within-sample forecast performance over 1960:2-1990:12, we see that BVARs offer a considerable improvement relative to the naive model, with average Theil U statistics of $0.69,0.63$, and 0.63 for $(T E)^{m 1},(T E)^{m 2}$, and $(T E)^{m 3}$ respectively. In-sample forecasts of the benchmark rate from the BVARs are also much better than from the no-change forecast. In addition, consistent with the results of the out-of sample forecast, table 15 shows that within-sample forecast performance of the BVARs, at the longer horizons outperform the naive model, in forecasting $(T E)^{m 1},(T E)^{m 2}$, and $(T E)^{m 3}$, and the benchmark rate.

Based on forecast performance results, we chose the AVAR and BVAR models to generate forecasts of total monetary-services expenditure and the benchmark rate. The reason that we chose AVAR over UVAR is that, based on out-of-sample forecast performance, AVAR models outperformed their UVAR counterpart. Although, based on in-sample forecast performance, UVAR models marginally outperformed their AVAR counterpart, we are more interested in out-of-sample forecast performance. Based on AVARs and BVARs, we generate two sets of forecasts for $(T E)^{m 1},(T E)^{m 2}$, and $(T E)^{m 3}$ and the corresponding benchmark rate.

It is worthwhile to note the gains from BVAR forecasting. We have estimated BVARs in log level, and evaluated forecast performance based on Theil's $U$ statistic. In computing the ESM, forecasts of variables in the ESM formula that outperform no-change forecasts of those variables should permit more accurate measures of ESM than available from the martingale forecast assumption implied by the CE index. To facilitate direct comparison with the $\mathrm{CE}$ index, we therefore compute the economic stock of money using BVAR forecasts of total expenditure and the benchmark rate. 
Table 6. Out-of-Sample Forecast Performance across Forecasting Horizons: UVAR-M1 and AVAR-M1 (Evaluation period: 1991:1-2004:3)

\begin{tabular}{|l|l|l|l|l|}
\hline \multirow{2}{*}{ Horizons } & \multicolumn{2}{|l|}{$(\text { TE })^{m 1}$} & \multicolumn{2}{l|}{ BENCH } \\
\cline { 2 - 5 } & UVAR-M1 & AVAR-M1 & UVAR-M1 & AVAR-M1 \\
\cline { 2 - 5 } & Average U & Average U & Average U & Average U \\
\hline 1 to 6 horizons & 0.80644 & 0.74948 & 0.88295 & 0.80808 \\
\hline 7 to 12 horizons & 0.74991 & 0.72132 & 0.80473 & 0.72917 \\
\hline 13 to 18 horizons & 0.72159 & 0.70829 & 0.73555 & 0.70539 \\
\hline 19 to 24 horizons & 0.75308 & 0.74339 & 0.77023 & 0.74541 \\
\hline 25 to 30 horizons & 0.76924 & 0.76288 & 0.77304 & 0.76125 \\
\hline 31 to 36 horizons & 0.73616 & 0.73218 & 0.72269 & 0.71707 \\
\hline 37 to 42 horizons & 0.71737 & 0.71525 & 0.71348 & 0.71485 \\
\hline 43 to 48 horizons & 0.70813 & 0.70416 & 0.69335 & 0.69566 \\
\hline
\end{tabular}


Table 7. Out-of-Sample Forecast Performance across Forecasting Horizons: UVAR-M2 and AVAR-M2 (Evaluation period: 1991:1-2004:3)

\begin{tabular}{|l|l|l|l|l|}
\hline \multirow{2}{*}{ Horizons } & \multicolumn{2}{|l|}{$(\text { TE })^{m 2}$} & \multicolumn{2}{l}{ BENCH } \\
\cline { 2 - 5 } & UVAR-M2 & AVAR-M2 & UVAR-M2 & AVAR-M2 \\
\cline { 2 - 5 } & Average U & Average U & Average U & Average U \\
\hline 1 to 6 horizons & 0.752 & 0.727 & 0.881 & 0.807 \\
\hline 7 to 12 horizons & 0.720 & 0.718 & 0.791 & 0.733 \\
\hline 13 to 18 horizons & 0.687 & 0.681 & 0.735 & 0.735 \\
\hline 19 to 24 horizons & 0.722 & 0.719 & 0.762 & 0.744 \\
\hline 25 to 30 horizons & 0.752 & 0.751 & 0.767 & 0.761 \\
\hline 31 to 36 horizons & 0.724 & 0.724 & 0.722 & 0.717 \\
\hline 37 to 42 horizons & 0.714 & 0.714 & 0.715 & 0.714 \\
\hline 43 to 48 horizons & 0.690 & 0.690 & 0.696 & 0.695 \\
\hline
\end{tabular}

Table 8. Out-of-Sample Forecast Performance across Forecasting Horizons: UVAR-M3 and AVAR-M3 (Evaluation period: 1991:1-2004:3)

\begin{tabular}{|l|l|l|l|l|}
\hline \multirow{2}{*}{ Horizons } & \multicolumn{2}{|l|}{$(\text { TE })^{m 3}$} & \multicolumn{2}{l|}{ BENCH } \\
\cline { 2 - 5 } & UVAR-M3 & AVAR-M3 & UVAR-M3 & AVAR-M3 \\
\cline { 2 - 5 } & Average U & Average U & Average U & Average U \\
\hline 1 to 6 horizons & 0.744 & 0.729 & 0.891 & 0.808 \\
\hline 7 to 12 horizons & 0.715 & 0.718 & 0.793 & 0.733 \\
\hline 13 to 18 horizons & 0.685 & 0.681 & 0.736 & 0.712 \\
\hline 19 to 24 horizons & 0.722 & 0.720 & 0.762 & 0.744 \\
\hline 25 to 30 horizons & 0.754 & 0.754 & 0.766 & 0.762 \\
\hline 31 to 36 horizons & 0.732 & 0.731 & 0.721 & 0.717 \\
\hline 37 to 42 horizons & 0.721 & 0.721 & 0.716 & 0.715 \\
\hline 43 to 48 horizons & 0.702 & 0.702 & 0.697 & 0.696 \\
\hline
\end{tabular}


Table 9. Out-of-Sample Forecast Performance across Forecasting Horizons: BVAR (Evaluation period: 1991:1-2001:12)

\begin{tabular}{|c|c|c|c|c|c|c|}
\hline \multirow{3}{*}{ Horizons } & \multicolumn{2}{|l|}{ BVAR-M1 } & \multicolumn{2}{|l|}{ BVAR-M2 } & \multicolumn{2}{|l|}{ BVAR-M3 } \\
\hline & $(\mathbf{T E})^{m 1}$ & BENCH & $(\mathbf{T E})^{m 2}$ & BENCH & $(\mathbf{T E})^{m 3}$ & BENCH \\
\hline & Average U & Average U & Average U & Average U & Average U & Average U \\
\hline 1 to 6 & 0.974 & 0.960 & 0.985 & 0.962 & 0.975 & 0.961 \\
\hline 7 to 12 & 0.942 & 0.910 & 0.969 & 0.911 & 0.950 & 0.909 \\
\hline 13 to 18 & 0.921 & 0.870 & 0.954 & 0.869 & 0.924 & 0.867 \\
\hline 19 to 24 & 0.90 & 0.844 & 0.927 & 0.841 & 0.872 & 0.838 \\
\hline 25 to 30 & 0.897 & 0.828 & 0.903 & 0.823 & 0.825 & 0.819 \\
\hline 31 to 36 & 0.892 & 0.818 & 0.901 & 0.810 & 0.825 & 0.807 \\
\hline 37 to 42 & 0.913 & 0.835 & 0.908 & 0.822 & 0.840 & 0.819 \\
\hline 43 to 48 & 0.974 & 0.846 & 0.922 & 0.831 & 0.851 & 0.827 \\
\hline
\end{tabular}

Table 10. Out-of-Sample Forecast Performance across Forecasting Horizons: BVAR (Evaluation period: 2002:1-2004:3)

\begin{tabular}{|l|l|l|l|l|l|l|}
\hline \multirow{2}{*}{ Horizons } & \multicolumn{2}{|l|}{ BVAR-M1 } & \multicolumn{2}{l|}{ BVAR-M2 } & \multicolumn{2}{l|}{ BVAR-M3 } \\
\cline { 2 - 7 } & $(\mathbf{T E})^{m 1}$ & BENCH & $\mathbf{~ ( T E ) ~}^{m 2}$ & BENCH & (TE) ${ }^{m 3}$ & BENCH \\
\cline { 2 - 7 } & Average U & Average U & Average U & Average U & Average U & Average U \\
\hline 1 to 6 & 1.06922 & 0.92638 & 1.024 & 0.923 & 1.040 & 0.930 \\
\hline 7 to 12 & 1.30507 & 0.80565 & 1.172 & 0.796 & 1.276 & 0.816 \\
\hline 13 to 18 & 1.44586 & 0.76427 & 1.332 & 0.755 & 1.490 & 0.779 \\
\hline 19 to 24 & 1.60524 & 0.71905 & 1.506 & 0.71 & 1.772 & 0.739 \\
\hline 25 to 27 & 1.67088 & 0.70160 & 1.450 & 0.699 & 1.815 & 0.729 \\
\hline
\end{tabular}


Table 11. Within-Sample Forecast Performance Statistics: Evaluation Period (1960:2-1990:12)

\begin{tabular}{|c|c|c|c|c|c|}
\hline \multicolumn{2}{|l|}{ UVAR-M1 } & \multicolumn{2}{|l|}{ AVAR-M1 } & \multicolumn{2}{|l|}{ BVAR-M1 } \\
\hline$(\mathrm{TE})^{m 1}$ & BENCH & $(\mathrm{TE})^{m 1}$ & BENCH & $(\mathrm{TE})^{m 1}$ & BENCH \\
\hline Average U & Average U & Average U & Average U & Average U & Average U \\
\hline 0.665 & 0.650 & 0.670 & 0.658 & 0.694 & 0.763 \\
\hline \multicolumn{2}{|l|}{ UVAR-M2 } & \multicolumn{2}{|l|}{ AVAR-M2 } & \multicolumn{2}{|l|}{ BVAR-M2 } \\
\hline$(\mathrm{TE})^{m 2}$ & BENCH & $(\mathrm{TE})^{m 2}$ & $\mathrm{BENCH}$ & $(\mathrm{TE})^{m 2}$ & $\mathrm{BENCH}$ \\
\hline 0.678 & 0.648 & 0.684 & 0.654 & 0.637 & 0.758 \\
\hline \multicolumn{2}{|l|}{ UVAR-M3 } & \multicolumn{2}{|l|}{ AVAR-M3 } & \multicolumn{2}{|l|}{ BVAR-M3 } \\
\hline$(\mathrm{TE})^{m 2}$ & BENCH & $(\mathrm{TE})^{m 2}$ & BENCH & $(\mathrm{TE})^{m 3}$ & BENCH \\
\hline 0.681 & 0.648 & 0.687 & 0.655 & 0.634 & 0.759 \\
\hline
\end{tabular}

Table 12. Within-Sample Forecast Performance Statistics across Forecasting Horizons:

UVAR-M1 and AVAR-M1, Evaluation Period (1960:2-1990:12)

\begin{tabular}{|l|l|l|l|l|}
\hline \multirow{2}{*}{ Horizons } & \multicolumn{2}{|c|}{ (TE) $^{m 1}$} & \multicolumn{2}{|c|}{ BENCH } \\
\cline { 2 - 5 } & UVAR-M1 & AVAR-M1 & UVAR-M1 & AVAR-M1 \\
\cline { 2 - 5 } & Average U & Average U & Average U & Average U \\
\hline 1 to 6 horizons & 0.617 & 0.639 & 0.587 & 0.613 \\
\hline 7 to 12 horizons & 0.661 & 0.667 & 0.649 & 0.659 \\
\hline 13 to 18 horizons & 0.687 & 0.688 & 0.680 & 0.678 \\
\hline 19 to 24 horizons & 0.669 & 0.669 & 0.658 & 0.657 \\
\hline 25 to 30 horizons & 0.671 & 0.672 & 0.660 & 0.665 \\
\hline 31 to 36 horizons & 0.683 & 0.684 & 0.660 & 0.667 \\
\hline 37 to 42 horizons & 0.669 & 0.672 & 0.655 & 0.661 \\
\hline 43 to 48 horizons & 0.671 & 0.673 & 0.656 & 0.664 \\
\hline
\end{tabular}


Table 13. Within-Sample Forecast Performance Statistics across Forecasting Horizons:

UVAR-M2 and AVAR-M2, Evaluation Period (1960:2-1990:12)

\begin{tabular}{|c|c|c|c|c|}
\hline \multirow{3}{*}{ Horizons } & \multicolumn{2}{|l|}{$(\mathbf{T E})^{m 2}$} & \multicolumn{2}{|l|}{ BENCH } \\
\hline & UVAR-M2 & AVAR-M2 & UVAR-M2 & AVAR-M2 \\
\hline & Average $\mathrm{U}$ & Average U & Average U & Average U \\
\hline 1 to 6 horizons & 0.632 & 0.650 & 0.584 & 0.609 \\
\hline 7 to 12 horizons & 0.666 & 0.678 & 0.641 & 0.655 \\
\hline 13 to 18 horizons & 0.683 & 0.686 & 0.676 & 0.672 \\
\hline 19 to 24 horizons & 0.686 & 0.688 & 0.656 & 0.654 \\
\hline 25 to 30 horizons & 0.685 & 0.687 & 0.660 & 0.662 \\
\hline 31 to 36 horizons & 0.702 & 0.705 & 0.661 & 0.665 \\
\hline 37 to 42 horizons & 0.683 & 0.687 & 0.654 & 0.659 \\
\hline 43 to 48 horizons & 0.690 & 0.694 & 0.655 & 0.662 \\
\hline
\end{tabular}

Table 14. Within-Sample Forecast Performance Statistics across Forecasting Horizons:

UVAR-M3 and AVAR-M3, Evaluation Period (1960:2-1990:12)

\begin{tabular}{|c|c|c|c|c|}
\hline \multirow{3}{*}{ Horizons } & \multicolumn{2}{|l|}{$(\mathbf{T E})^{m 3}$} & \multicolumn{2}{|l|}{ BENCH } \\
\hline & UVAR-M3 & AVAR-M3 & UVAR-M3 & AVAR-M3 \\
\hline & Average U & Average U & Average U & Average U \\
\hline 1 to 6 horizons & 0.635 & 0.653 & 0.582 & 0.608 \\
\hline 7 to 12 horizons & 0.667 & 0.679 & 0.640 & 0.655 \\
\hline 13 to 18 horizons & 0.684 & 0.686 & 0.677 & 0.672 \\
\hline 19 to 24 horizons & 0.689 & 0.691 & 0.657 & 0.654 \\
\hline 25 to 30 horizons & 0.690 & 0.692 & 0.660 & 0.662 \\
\hline 31 to 36 horizons & 0.708 & 0.71 & 0.6662 & 0.665 \\
\hline 37 to 42 horizons & 0.687 & 0.69 & 0.655 & 0.659 \\
\hline 43 to 48 horizons & 0.694 & 0.697 & 0.655 & 0.662 \\
\hline
\end{tabular}


Table 15. Within-Sample Forecast Performance Statistics across Forecasting Horizons: BVAR, Evaluation Period (1960:2-1990:12)

\begin{tabular}{|l|l|l|l|l|l|l|}
\hline \multirow{2}{*}{ Horizons } & \multicolumn{2}{|l|}{ BVAR_M1 } & \multicolumn{2}{l|}{ BVAR_M2 } & \multicolumn{2}{l|}{ BVAR_M3 } \\
\cline { 2 - 7 } & $(\mathbf{T E})^{m 1}$ & BENCH & $\left.\mathbf{~}^{\mathrm{T}}\right)^{m 2}$ & BENCH & (TE) $^{m 3}$ & BENCH \\
\cline { 2 - 7 } & Avg. U & Avg. U & Avg.U & Avg.U & Avg.U & Avg.U \\
\hline 1 to 6 horizons & 0.923 & 0.924 & 0.913 & 0.925 & 0.916 & 0.925 \\
\hline 7 to 12 horizons & 0.853 & 0.898 & 0.816 & 0.896 & 0.818 & 0.897 \\
\hline 13 to 18 horizons & 0.759 & 0.812 & 0.711 & 0.808 & 0.714 & 0.809 \\
\hline 19 to 24 horizons & 0.702 & 0.759 & 0.640 & 0.755 & 0.639 & 0.755 \\
\hline 25 to 30 horizons & 0.648 & 0.722 & 0.570 & 0.717 & 0.563 & 0.718 \\
\hline 31 to 36 horizons & 0.586 & 0.679 & 0.501 & 0.672 & 0.491 & 0.673 \\
\hline 37 to 42 horizons & 0.541 & 0.648 & 0.462 & 0.641 & 0.455 & 0.642 \\
\hline 43 to 48 horizons & 0.495 & 0.626 & 0.428 & 0.618 & 0.424 & 0.619 \\
\hline
\end{tabular}

\section{Empirical Results: Estimation of Money Stock}

We have derived and formally defined the ESM in a manner consistent with aggregation theory and capital asset pricing theory. We compare the CE and SSI relative to the ESM in much the same way that consumer price indexes are routinely compared with the true cost of living index, similarly derived from microeconomic aggregation theory. But since the ESM depends upon unmeasurable future variables, we cannot conduct those comparisons without an approach to approximating future expectations. ${ }^{26}$ We consider use of actual future values along with VAR forecasted values by various methods. It is not our intention in this paper to advocate any particular approach to modeling future expectations. But our limited conclusions in this paper prove to be highly robust to the approaches we use for modeling expectations. Stronger results, anticipated from our future research, will require design of an index number than can remove the small bias that we

\footnotetext{
${ }^{26}$ As with the true cost of living index, there also are complications that can be produced by heterogeneity of tastes and nonhomotheticity. We do not investigate those problems for either the consumer price index or the ESM in this paper.
} 
identify in the otherwise easily measured CE index.

\subsection{Economic Stock of Money Computed using Actual Data}

First, we assume perfect foresight and compute the ESM using actual future data for monetary-services expenditure and the benchmark asset's rate of return. ${ }^{27}$ We use the formula for $V_{t}$ given by equation (3.7). Although future values cannot be known ahead of time, the ESM computed using actual future data provides a useful yardstick in assessing the ESM computed using forecasted values. With actual data available through 2004:3, we were able to compute and display the economic stock of money up to 1991:9. ${ }^{28}$ To facilitate comparisons among different money stock measures, all figures contain simple-sum aggregates and the CE aggregates, as well as the economic stock aggregates. For the $\mathrm{CE}$ index, we computed not only the contemporaneous $\mathrm{CE}$ index that uses

the current weight, $\frac{R_{t}-r_{i t}}{R_{t}}$, for each asset, but also the smoothed CE index. In smoothing the volatile contemporaneous CE index, Rotemberg, Driscoll, and Poterba (1995) used centered moving averages of the weights. Following the same smoothing procedure, we computed smoothed CE index by replacing weights of monetary assets with 13-month centered moving averages of the weights. At the start and end of the sample, when symmetric centered moving averages are not available, asymmetric uncentered moving averages of the weights were used.

Figures 1, 2, and 3 in Barnett, Chae, and Keating (2005) show ESM1_actual, ESM2_actual, and ESM3_actual, respectively, from 1959:1 through 1991:9, where ESM1_actual, ESM2_actual, and ESM3_actual denote the ESM computed using actual future data at each level of aggregation, while CE_mov13 denotes the CE aggregates computed using 13-month centered moving averages of the weights.

Figure 1 in this paper along with figures in Barnett, Chae, and Keating (2005) present the size of the

\footnotetext{
${ }^{27}$ Since our objective is to investigate robustness to expectations, we are not taking perfect certainty literally. In fact, if there really were perfect certainty, some of the motives for holding money would disappear (but not all such motives, such as the "cash in advance Clower constraint" motive).

${ }^{28}$ The stopping point was determined by the convergence criterion in equation (4.2).
} 
errors in the SSI aggregates, both in terms of levels and percentages. ${ }^{29}$ As shown in those figures, the size of the error in SSIM1 is relatively small, but the errors increase as the level of aggregation gets broader. This result is not a surprising, since higher level of monetary aggregation includes more market-interest-yielding money assets. Those assets, providing significant investment yield, are weighted the same as currency in the SSI aggregates.

On the other hand, the gap between the ESM and the CE index represents the CE index's bias, resulting from its implicit assumption of martingale expectations. The figures in Barnett, Chae, and Keating show that the CE index underestimates its ESM counterparts almost always, except for CEM2 and CEM3 during the late 1980s. However, the gaps between the CE index and their ESM_actual counterparts are very small, particularly early in the sample period. The gap between the ESM_actual and the smoothed CE index over time is presented more clearly in figure 2 below. The gap is presented relative to ESM_actual by dividing the gap by ESM_actual. The exception to downward bias of the CEM2 and CEM3 occurs only between 1987:7 and 1989:2. In addition, the gap between the ESM and the CE index appears to be growing after 1989. Comparing volatility of the CE index with that of the ESM_actual, we have found that the unsmoothed CEM1 is a slightly more volatile than the ESM1_actual, while the unsmoothed CEM2 and CEM3 are significantly more volatile than their ESM_actual counterparts. However, CEM2_mov13 and CEM3_mov13 are much less volatile than the unsmoothed index. The volatilities of the smoothed CEMs are similar to those of the ESMs_actual.

To examine quantitatively the errors in the SSI and the CE index, Barnett, Chae, and Keating (2005) decomposed the SSI into its monetary service share and non-monetary service share (investment yield share). ${ }^{30}$ This decomposition explicitly recognizes that interest-bearing monetary assets are joint products providing both monetary services and investment yield services. Table 7 in Barnett, Chae, and Keating (2005) reports monetary services share percentage and investment share percentage for the SSI relative to the

\footnotetext{
${ }^{29}$ This approach to measuring the size of the simple sum stock bias was first introduced by Barnett and Zhou (1994).

${ }^{30}$ As described in section 3, the concept of "monetary" services is a residual following removal of non-monetary services. In the history of economic thought, the most clearly identified non-monetary service is investment yield. But that yield can be augmented by the imputed return on other services chosen to be viewed as non-monetary, as most frequently done to produce implicit rates of return on rate-regulated monetary assets. See, e.g., Klein (1974).
} 
economic money stock and CE aggregate, which remove the investment motive from the discounted flow. They compute the monetary services share as $\frac{E S M}{S S I} * 100$ or $\frac{C E}{S S I} * 100$ and the investment share as $\frac{S S I-E S M}{S S I} * 100$ or $\frac{S S I-C E}{S S I} * 100$. The investment share is an error inherent in the SSI, which treats interest bearing money as a perfect substitute for non-interest bearing currency.

Over the sample period from 1959:1 to 1991:9, the decomposition relative to the ESM_actual suggests that the simple sum M1 index contains non-monetary services share of $25.32 \%$, while the simple sum M2 and M3 indexes include non-monetary services of $41.3 \%$ and $44.86 \%$, respectively. This clearly shows that bias contained in the SSI aggregates grows as the level of aggregation increases. The decomposition of the SSI based on the CE index suggests that, over the same sample period, SSIM1, SSIM2, and SSIM3 contain investment shares of $29.68 \%, 46.02 \%$, and $49.44 \%$, respectively. These percentages are slightly greater than those implied by the ESM_actual data. Barnett, Chae, and Keating (2005) thereby find that when the $\mathrm{CE}$ index is used as the money stock measure, the $\mathrm{CE}$ aggregates underestimate economic money stock by $4.36 \%$ of SSIM1, $4.72 \%$ of SSIM2, and $4.58 \%$ of SSIM3. However, these biases in the CE index are relatively small, compared to the biases of $25.32 \%, 41.3 \%$, and $44.86 \%$ contained within SSI index. 


\section{Figure 1:}

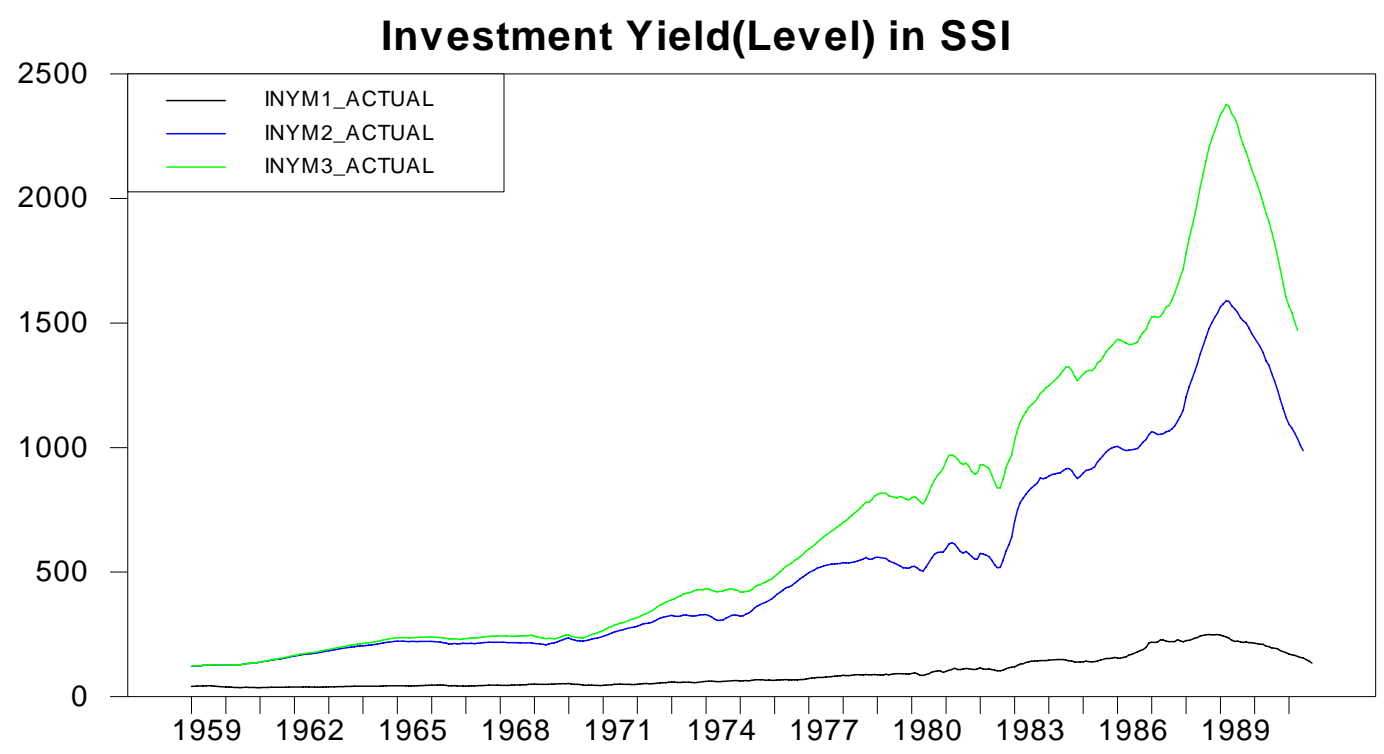

Note: Investment yield in level was computed by $(S S I-V)$ where $V$ is the ESM actual.

\section{Figure 2:}

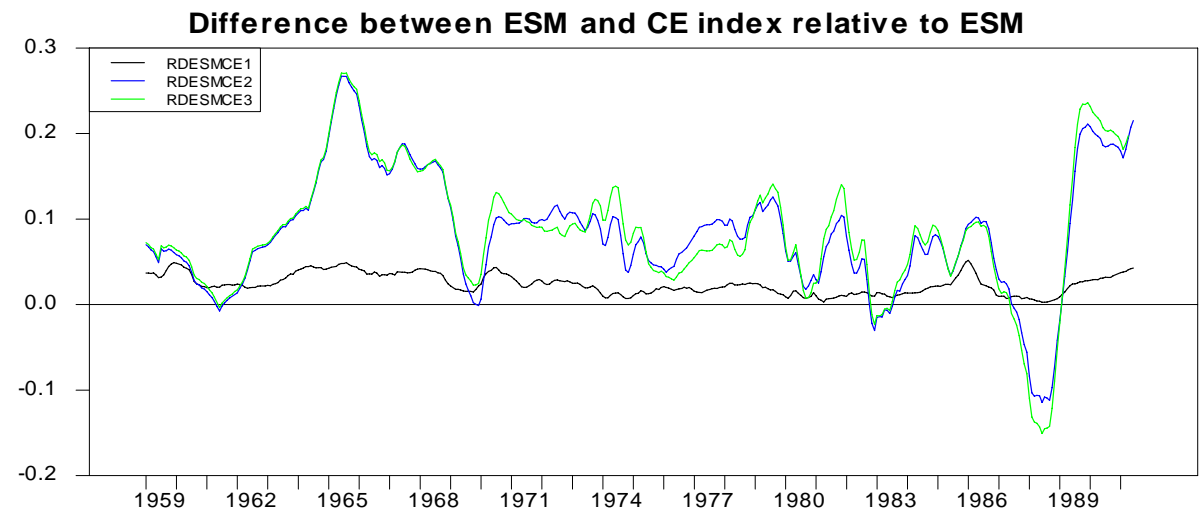

Note: RDESMCE is the error inherent in $\mathrm{CE}$ and was computed by subtracting CE from ESM_actual and then dividing by ESM_actual.

\subsection{Economic Stock of Money Based on BVAR and AVAR Forecasts}

In the previous section, the ESM was computed assuming perfect knowledge of the future. In this section, we compute the ESM using forecasts of the benchmark rate and monetary-services expenditure. The forecasts were generated using the BVAR and AVAR models. The models were first estimated using initial 
data from 1959:1 through 1990:12, and forecasts were then computed for up to 200 steps ahead. In each month from 1991:1 through 2004:3, the coefficients are updated sequentially by adding one more observation. Based on the resulting updated coefficients, a series of 200-step-ahead forecasts are computed. For the period 1959:1 to 1990:12 over which we estimated the forecasting models, we generated in-sample forecasts. For the period from 1991:1 to 2004:3, we generated out-of-sample forecasts.

For the period 2002:1 to 2004:3, the BVAR models produced less accurate forecasts for TEs than a naive model. As a result, for that period we replaced those BVAR total-expenditure forecasts with the martingale forecast, comprising the actual current value. Even in this case, the ESM should contain less error than the CE index, since we use a better forecast of the benchmark rate. The CE index uses the martingale forecast for both the TEs and the benchmark rate.

To compute the ESM, we use three methods proposed in equations (4.5), (4.3), and (4.7) of Barnett, Chae, and Keating (2005), which we call Methods 1, 2, and 3, respectively. Method 1 computes the ESM by a linear approximation around current values of the future values of monetary-services total expenditure and the benchmark rate. Method 2 imposes the martingale expectation assumption on only the benchmark rate. Method 3 ignores the effects of all covariance terms among benchmark rates in different periods and among benchmark rates and monetary services expenditures. The convergence criterion, used with all three methods, is provided by equation (4.2).

\subsubsection{ESM Computed Using Forecasts from BVAR}

Figures 5, 6, and 7 in Barnett, Chae, and Keating present ESM1, ESM2, and ESM3, computed using forecasts from the BVAR model with Method 1. The ESM computed using forecasts from BVAR with Method 1 is denoted by ESM_mtd1_BVAR. Figure 5 in that paper shows that ESM1_mtd1_BVAR is very close to ESM1_actual, especially in the early sample period. Observing the period after 1980, when the divergence of CEM1 from ESM1_actual begins to increase, we can observe that ESM1_mtd1_BVAR deviates less from ESM1_actual than the CEM1 does. However, during the same period, ESM2_mtd1_BVAR and ESM3_mtd1_BVAR are not much different from CEM2 and CEM3, in terms of their gaps with ESM2_actual and ESM3_actual, respectively.

The variation in errors in SSI over time is presented in this paper in figure 6, which is a graph against 
time of investment yield, measured by the gap between ESM_mtd1_BVAR and the SSI index. A related figure in Barnett, Chae, and Keating (2005) displays investment share as a percentage. In comparing ESM_mtd1_BVAR with the SSI index, we can observe the same patterns as those obtained in the previous section. The simple sum aggregates are biased upward, and the size of the errors in the SSI increases as the level of aggregation increases, as indicated by in figure 6 .

Also consistent with result in the previous section, we can see from Figure 7 that the CE aggregates are almost always biased downward, but the gap between ESM_mtd1_BVAR and the CE index is small. However, ESM_mtd1_BVAR appears to be more volatile than ESM_actual or smoothed CE index. As in Figure 2, the gap between CE and ESM is divided by ESM in Figure 7 to normalize for scale.

The increase in bias of SSI with the breadth of aggregation is clearly presented in Barnett, Chae, and Keating (2005). Relative to ESM_BVAR, the size of the errors in the SSI is very close to that measured by the gap between the SSI index and the ESM using actual data. Barnett, Chae, and Keating (2005) find that the CE index underestimates the ESM, but not significantly, with the errors in the CE index less than $4 \%$ of SSI index in all level of aggregates and all sub-sample periods. The investment shares in the second sub-period seem to be significantly lower than those in the first sub-sample period. The reason is shown in a figure in percentage form in Barnett, Chae, and Keating (2005). Over the period from 1991 to early 1994 and the period after 2001:4, there was a strong tendency for investment shares to decline. ${ }^{31}$ We can infer that during these periods, the own rates of return on monetary assets, relative to the benchmark-asset rate of return, have decreased too.

\subsubsection{ESM Computed Using Forecasts from AVAR}

Figure 3, 4, and 5 show the ESM1, ESM2, and ESM3 computed using forecasts from AVAR model and method 1. We denote ESM computed using forecasts from AVAR model and method 1, method 2, and method 3 by ESM_mtd1_AVAR, ESM_mtd2_AVAR, and ESM_mtd3_AVAR, respectively.

ESM1_mtd1_AVAR, ESM2_mtd1_AVAR, and ESM3_mtd1_AVAR show much high volatility than those shown by counterpart ESM_mtd_BVAR. Nevertheless, they also show the same patterns as

ESM_mtd1_BVAR with respect to biases in the SSI and the CE index: The simple sum index is biased

\footnotetext{
${ }^{31}$ In this paper, we provide the investment yield itself in Figure 6, without division by V.
} 
upward while the CE index is biased downward, but not substantially.; The size of bias in simple sum aggregates increases with broader aggregates. Over sub-sample period from 1960:2 to 1991:9, ESM_mtd1_AVAR implies that the simple sum M1, M2, and M3 include non-monetary service of $27.25 \%$, $42.98 \%$, and $46.5 \%$, respectively. Even though the ESM based on forecasts of AVAR shows too high volatilities, its average level is almost same as that of ESM_mtd1_BVAR.

\subsubsection{Comparison across Computing Methods}

Graphs of the ESMs based on methods 2 and 3 are shown in figure 8-12 in the appendix. When comparing the ESM across computing methods, methods 1 and 3 resulted in almost identical values of the ESM at all levels of aggregation. As shown in Barnett, Chae, and Keating (2005), the difference between the two methods is even less than 1\%. On the other hand, comparing the ESMs based on methods 1 and 2 over the full sample period, we find that monetary service shares estimated by method 2 were greater than those estimated by method 1 , but the differences were less than $3 \%$ of the SSI at all levels of aggregation. The divergence between methods 12 results from the assumption of martingale expectations. In addition, Figure 8, 9, and 10 show that the ESMs based on method 2 are more volatile than those based on the two other methods. Nevertheless, the differences in economic money stock across computing methods seem to be negligibly small, relative to the overall bias in the SSI.

Furthermore, regardless of the forecast models from which forecasts are generated, and the methods by which ESM was computed, certain patterns are evident. The SSI is biased upwards. The bias inherent in the SSI increases as the level of aggregation increases. The CE index is biased downwards, with that bias being less than $4 \%$ of SSI. 
Figure 3: Using AVAR Forecasts

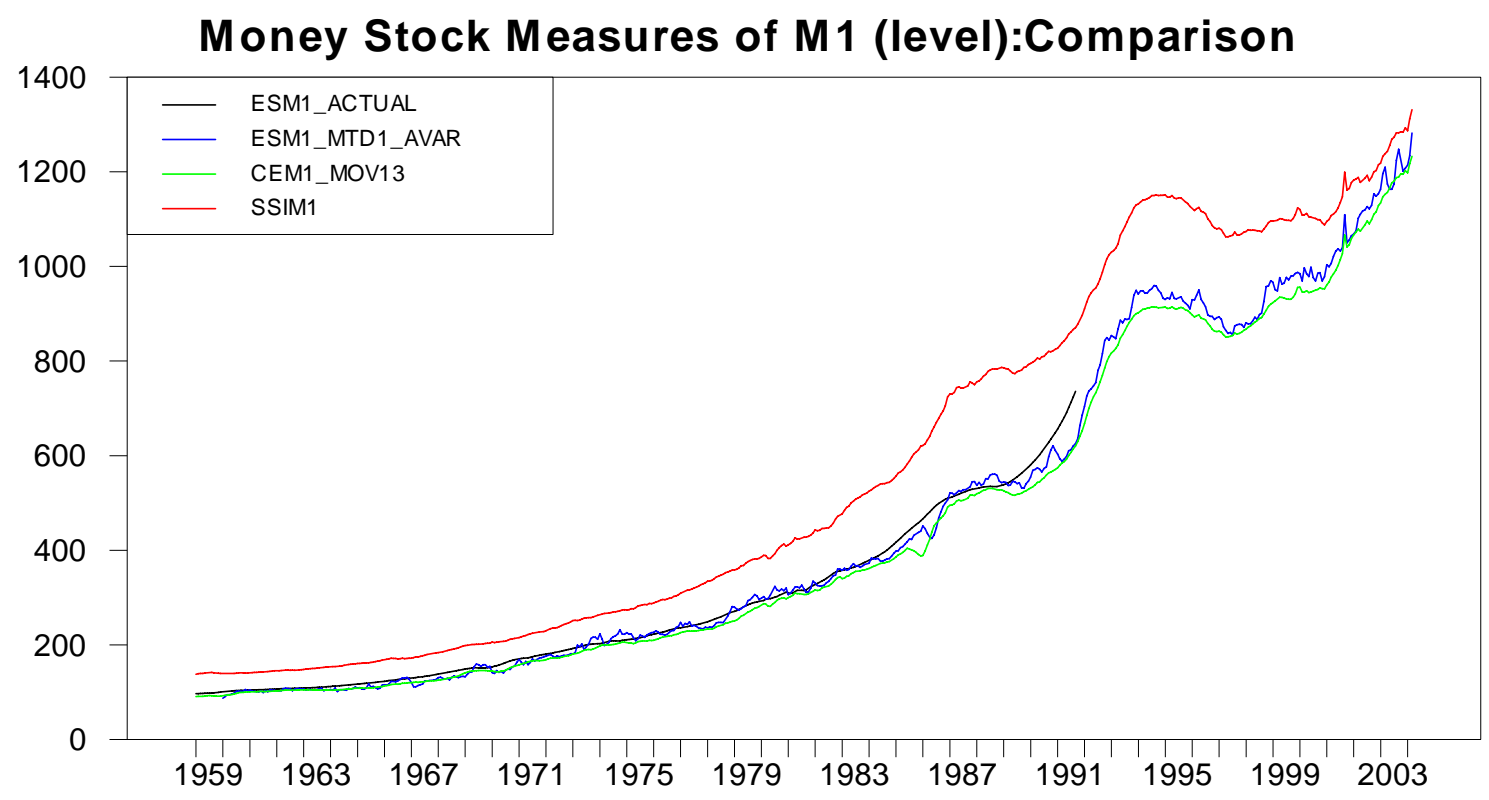

Note: ESM1_actual: Economic Stock of M1 computed using actual data

ESM1 mtd̄1 AVAR: Economic Stock of M1 computed using method 1 and forecasts from AVAR 
Figure 4: Using AVAR Forecasts

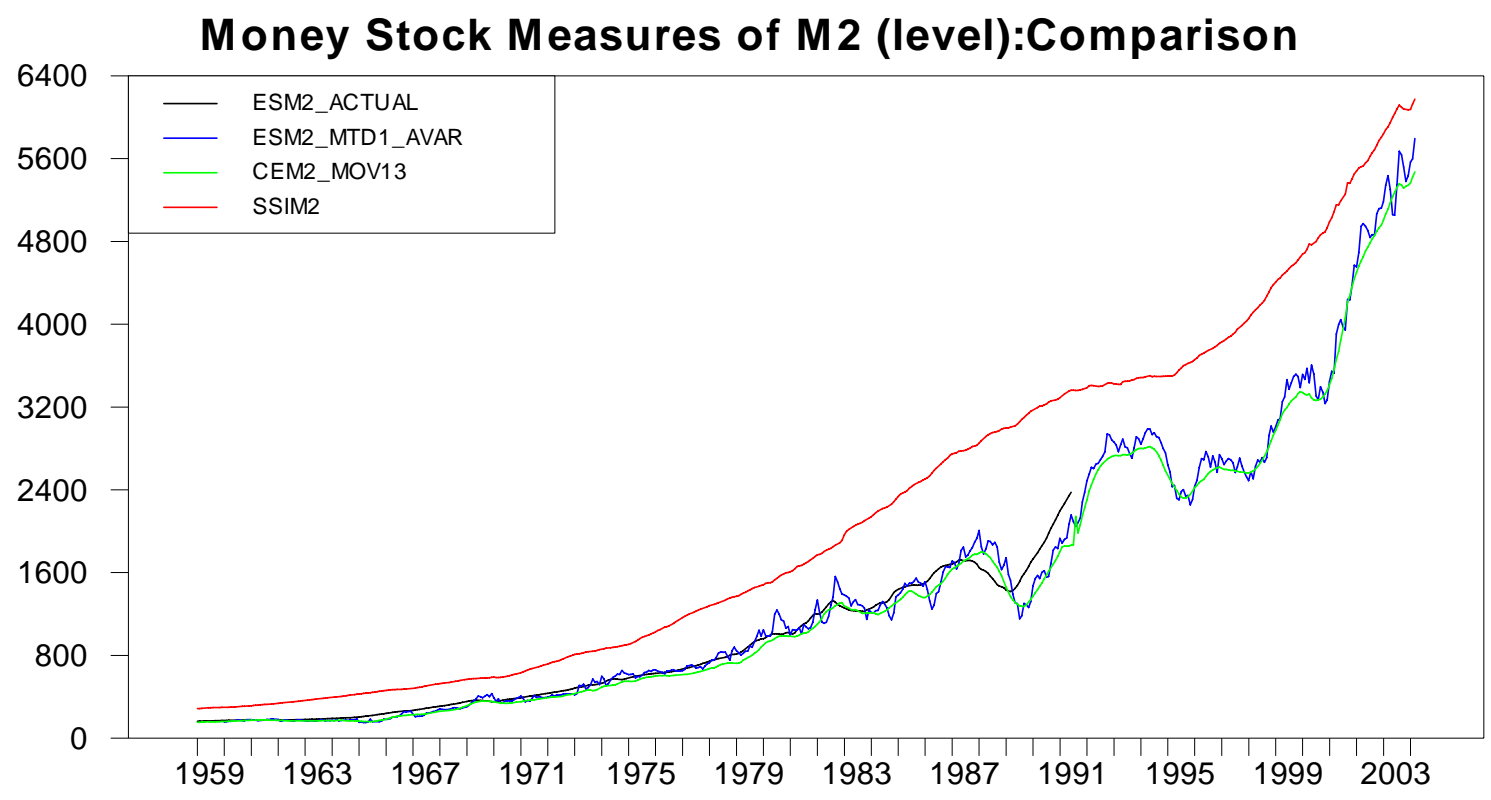

Note: ESM2_actual: Economic Stock of M2 computed using actual data

ESM2_mtd1_AVAR: Economic Stock of M2 computed using method 1 and forecasts from AVAR

Figure 5: Using AVAR Forecasts

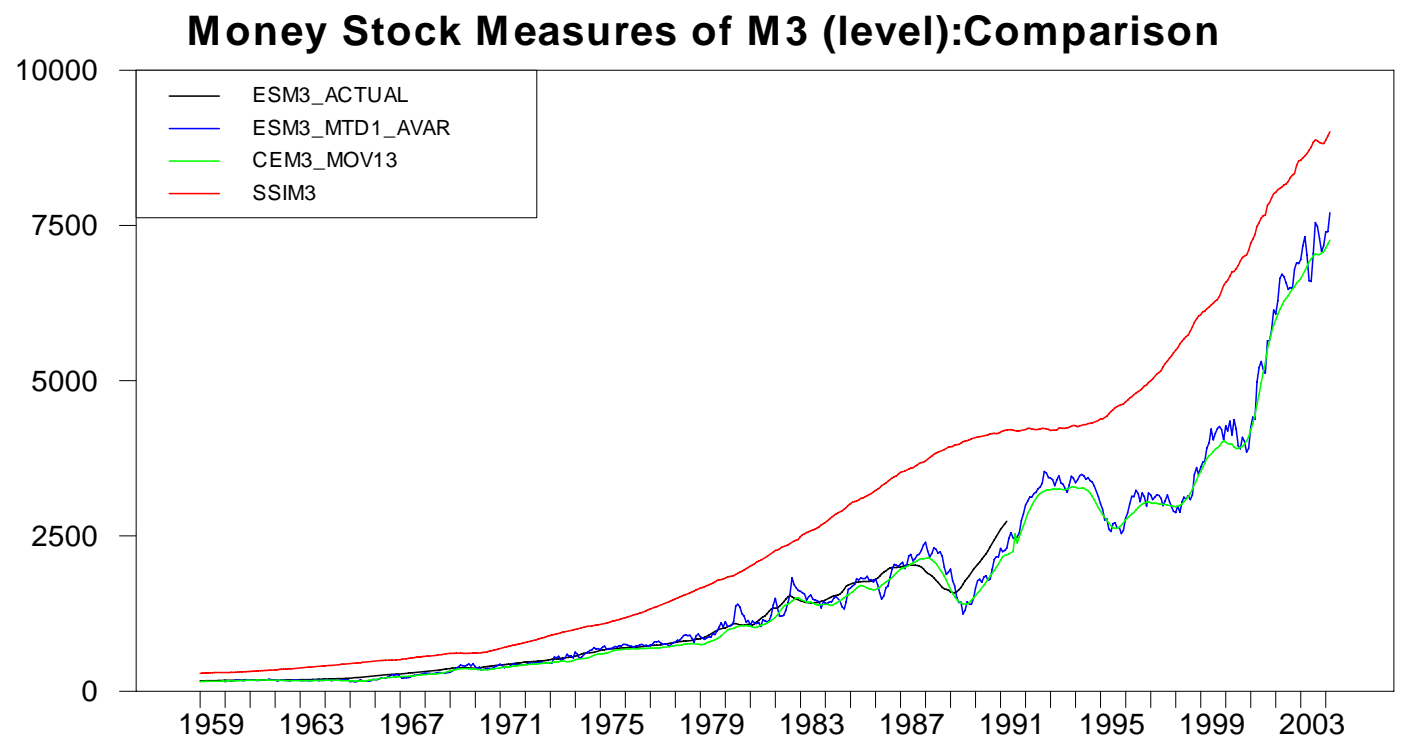

Note: ESM3_actual: Economic Stock of M3 computed using actual data

ESM3_mtd̄1_AVAR: Economic Stock of M3 computed using method 1 and forecasts from AVAR 
Figure 6:

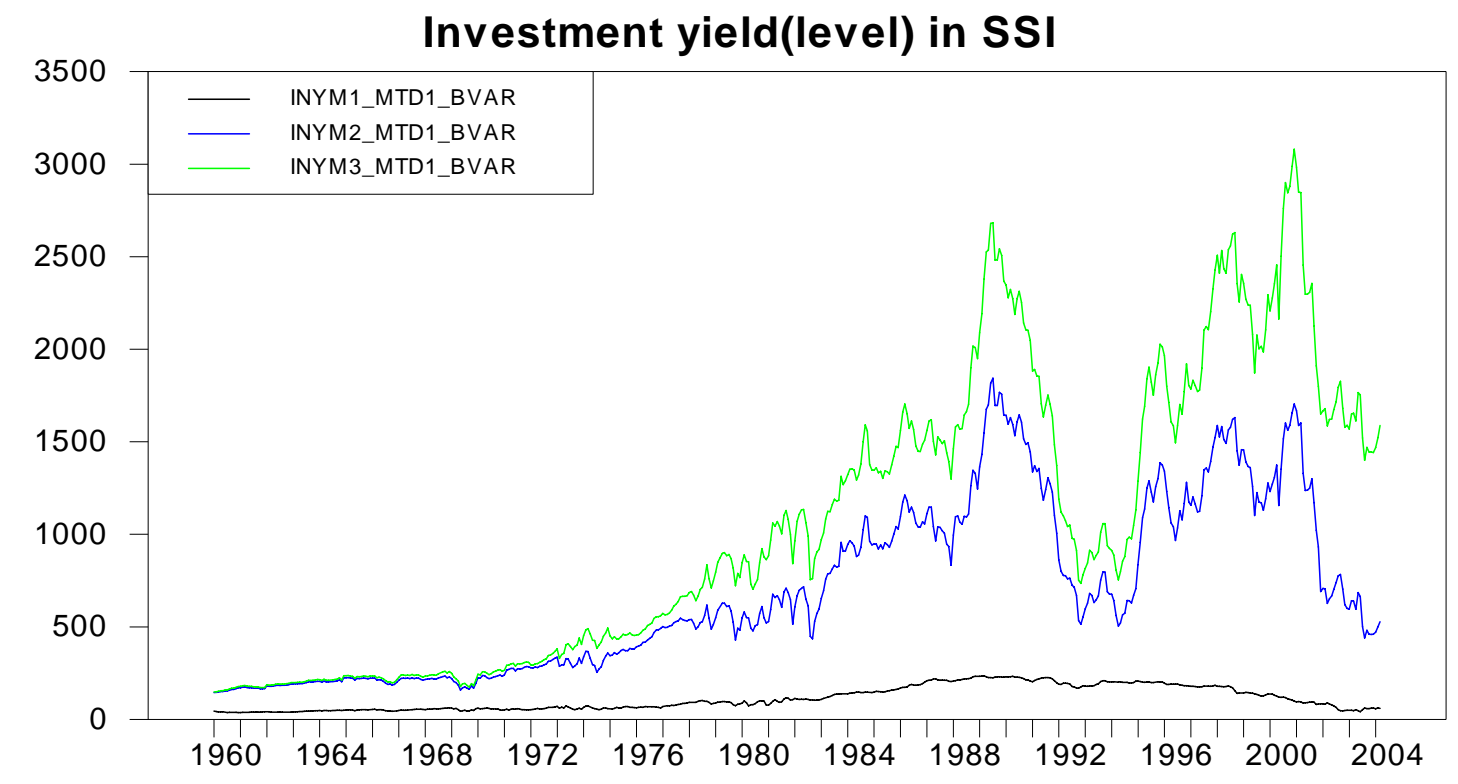

Note: INYM_MTD1_BVAR is level of investment yield inherent in SSI computed as (SSI-V) where $\overline{\mathrm{V}}$ is ESM_mtd1_BVAR 


\section{Figure 7:}

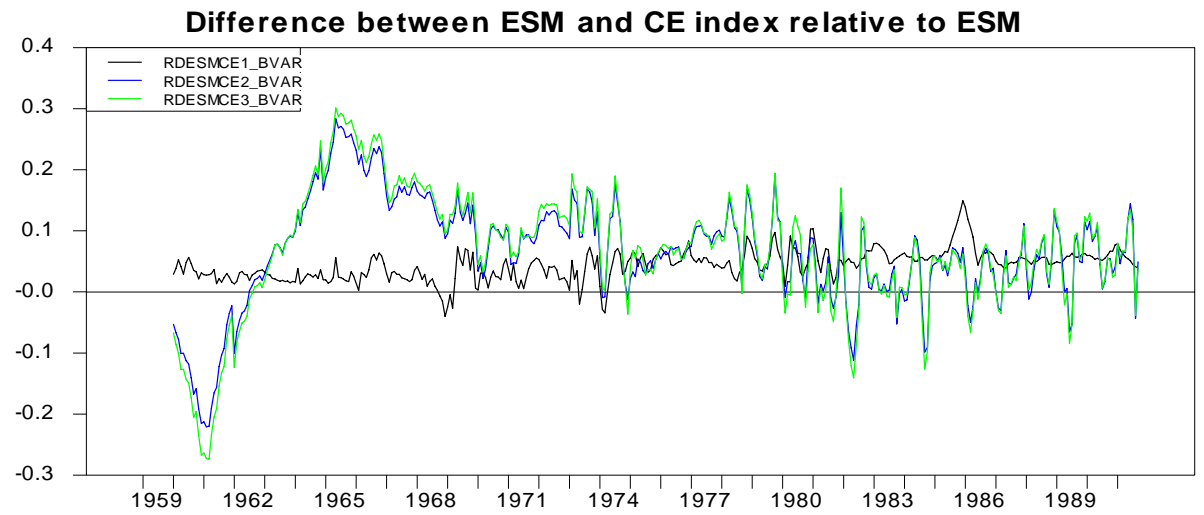

Note: DESMCE_BVAR is the error inherent in CE and computed by subtracting CE index from ESM_mtd1_BVAR and then dividing by ESM_mtd1_BVAR.

\section{Discussion and Conclusion}

We measure the United States capital stock of money implied by the Divisia monetary-services-flow index, in a manner consistent with present-value discounting and time-varying discount rates. Based on Barnett's (1991) definition of the economic capital stock of money, we compute the economic stock of money by discounting to present value the expected monetary-services-flow expenditure, with user cost pricing of those flows. The economic stock of money nests the currency equivalent (CE) index as a special case under the assumption of martingale expectations. While the martingale expectations assumption greatly simplifies the present-value discounting, that assumption is very strong and often has produced hesitancy to use the CE index as a stock measure. Instead of assuming martingale expectations, we use forecasts based on asymmetric vector autoregression (AVAR) and Bayesian vector autoregression (BVAR). For comparison, we compute the ESM using actual realized future data within our sample.

We report the size of biases embedded in the SSI and the CE index. Those biases can be attributed to the two indexes' implicit assumptions. The ESM computed using BVAR forecasts implies that the simple sum index greatly exaggerates money stock through inclusion of substantial non-monetary shares. Over the period 1960:2 to 2004:3, those non-monetary shares comprised $22.76 \%$ of the stock at the M1 level, $37.11 \%$ at the M2 level, and $41.26 \%$ at the M3 level of aggregation. The size of the bias of the SSI increases as the breadth of aggregation grows. 
The CE index almost always underestimated the economic stock of money, but the size of the bias in the CE index was less than $4 \%$ of the SSI index's bias at all levels of aggregation. Although the assumption of martingale expectations may be unappealing, the resulting bias of the CE index is very small compared with the bias of the SSI index. A particularly noteworthy conclusion of this research was the robustness of our results across forecasting models.

Prior concerns about the use of Barnett's economic capital stock of money have centered on the difficulties of discounting expected future flows and on the possible need to use sophisticated approaches of forecasting to acquire good results. We find that robustness to the forecasting method is not only high, but is so high that even the simple martingale expectations method implicit in the easily computed CE index is adequate for most purposes.

To do better than the CE index in measuring the growth rate of the monetary-asset capital stock, one can use our BVAR or AVAR model. They both outperformed the "naive" martingale forecast model implicit in the CE index. But data series that depend on forecasted variables are not likely to be preferred by governmental agencies, and we find the gains from forecasting to be small. Although based upon "naive" forecasting, the $\mathrm{CE}$ is not atheoretical, unlike the atheoretical simple-sum accounting index. In addition the $\mathrm{CE}$ index can easily be computed using data at a single point in time, with moving average smoothing of that otherwise highly volatile index.

In conclusion, the $\mathrm{CE}$ index can be used to measure the stock of money with reasonable accuracy, while the official simple-sum aggregate is an inappropriate measure of money stock or monetary-services flow. While the use of BVAR or AVAR forecasting can produce small gains for research purposes, we believe that the moving-average-smoothed CE index may be adequate for most policy purposes requiring a money stock variable. We believe using an appropriate measure of money stock can produce advances in understanding the wealth effects of policy. The prior hesitancy to use the theoretical economic capital-stock of money formula no longer is justified, since our finding of robustness of that formula to expectations formation removes the reason for that concern, when judged relative to the simple sum index.

In future research, we plan to design a statistical index number that can remove the small bias that 
we have identified in the CE index. ${ }^{32}$ Introduction of risk aversion also merits research, using the approach in Barnett and $\mathrm{Wu}(2005)$ to risk-adjust the flow that is discounted in the ESM. Having established merits of the asset-pricing capital-stock approach to money measurement, we leave such possible refinements to future research. But it is important to recognize that the large gain in moving from the simple-sum index to the ESM, computed with any forecasting procedure, far exceeds the gains from bias correction, risk adjustment, or choice among forecasting procedures.

\footnotetext{
${ }^{32}$ We plan to do so without the use of the smoothing procedure advocated by Rotemberg, Driscoll, and Poterba (1995), since that smoothing compromises the theory. But for consistency with the past literature, we have computed the CE in this paper with their smoothing filter. The smoothing advocated by Rotemberg, Driscoll, and Poterba has no effect on the bias we have identified, since that smoothing uses a centered, rather than forward-looking moving average.
} 


\section{APPENDIX}

Figure 8:

ESM1_method2

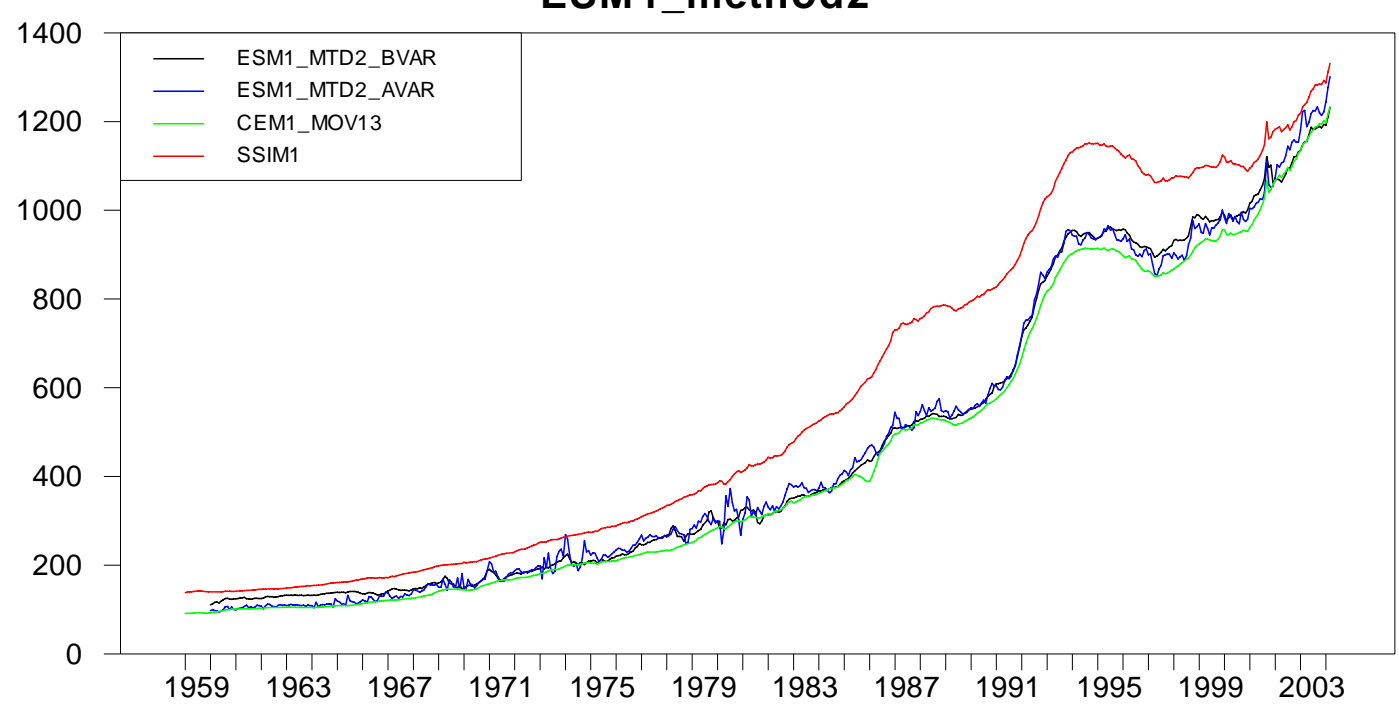

Note: ESM1 mtd2_AVAR: Economic Stock of M1 computed using method 2 and forecasts from AVAR ESM1 mtd2 BVAR: Economic Stock of M1 computed using method 2 and forecasts from BVAR 


\section{Figure 9:}

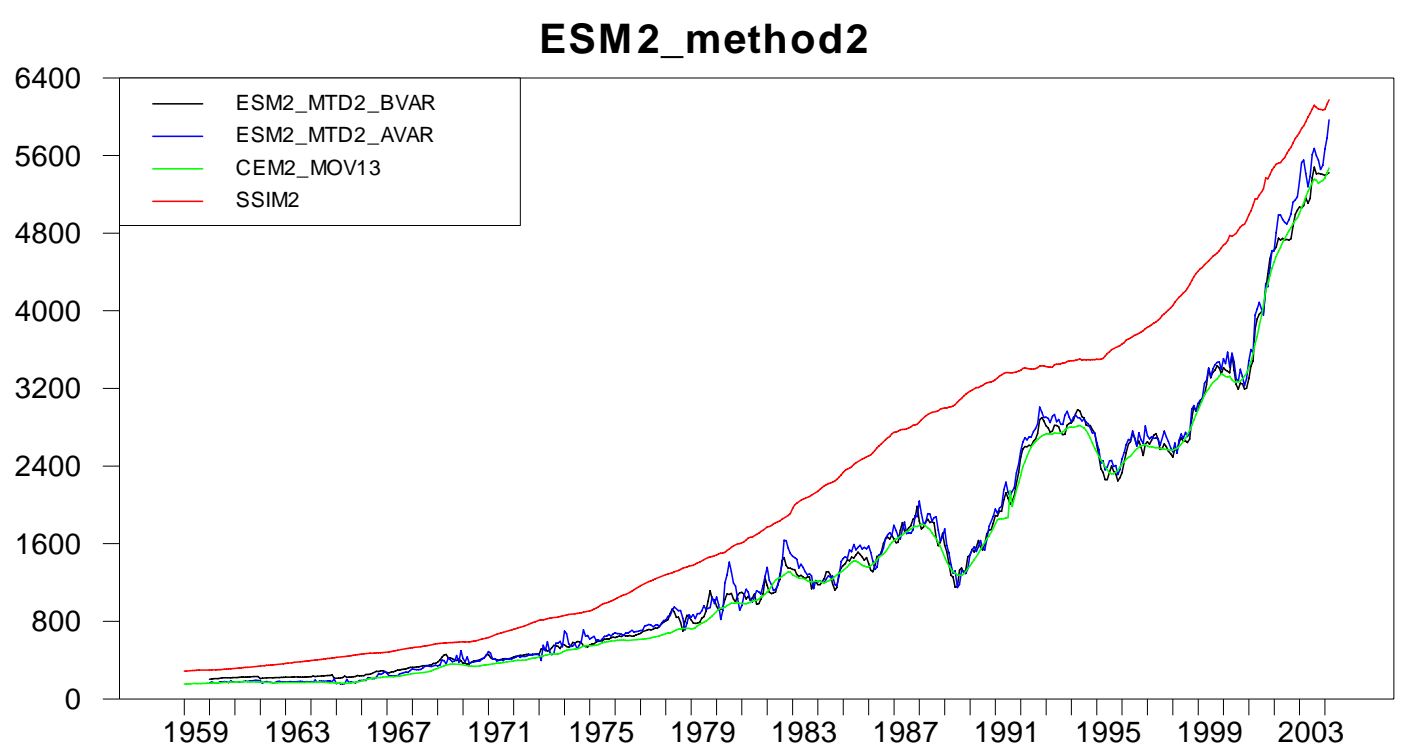

Note: ESM2 mtd2_AVAR: Economic Stock of M2 computed using method 2 and forecasts from AVAR ESM2 mtd2_BVAR: Economic Stock of M2 computed using method 2 and forecasts from BVAR 


\section{Figure 10:}

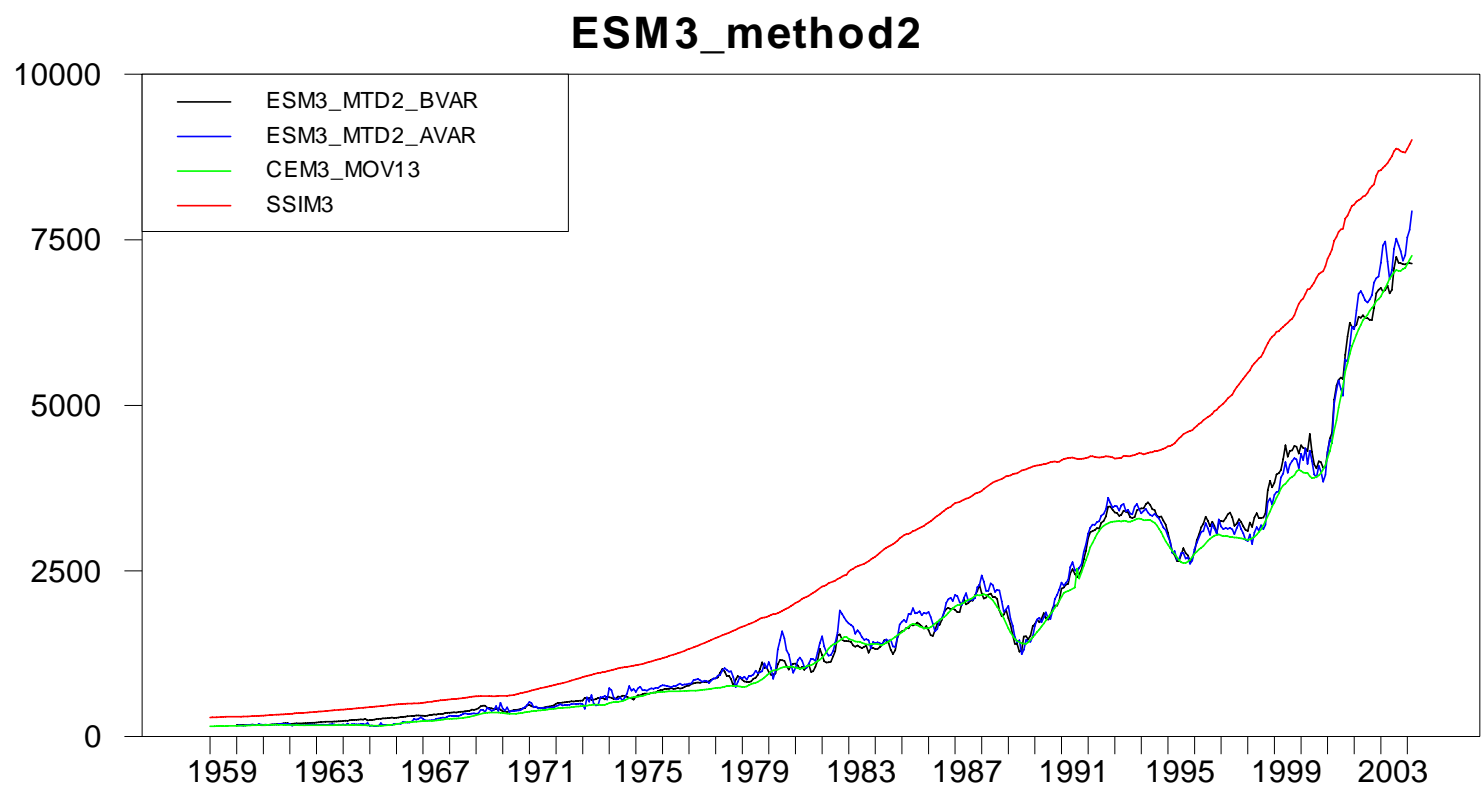

Note: ESM3_mtd2_AVAR: Economic Stock of M3 computed using method 2 and forecasts from AVAR

ESM3_mtd2_BVAR: Economic Stock of M3 computed using method 2 and forecasts from BVAR 


\section{Figure 11:}

\section{ESM1_method3}

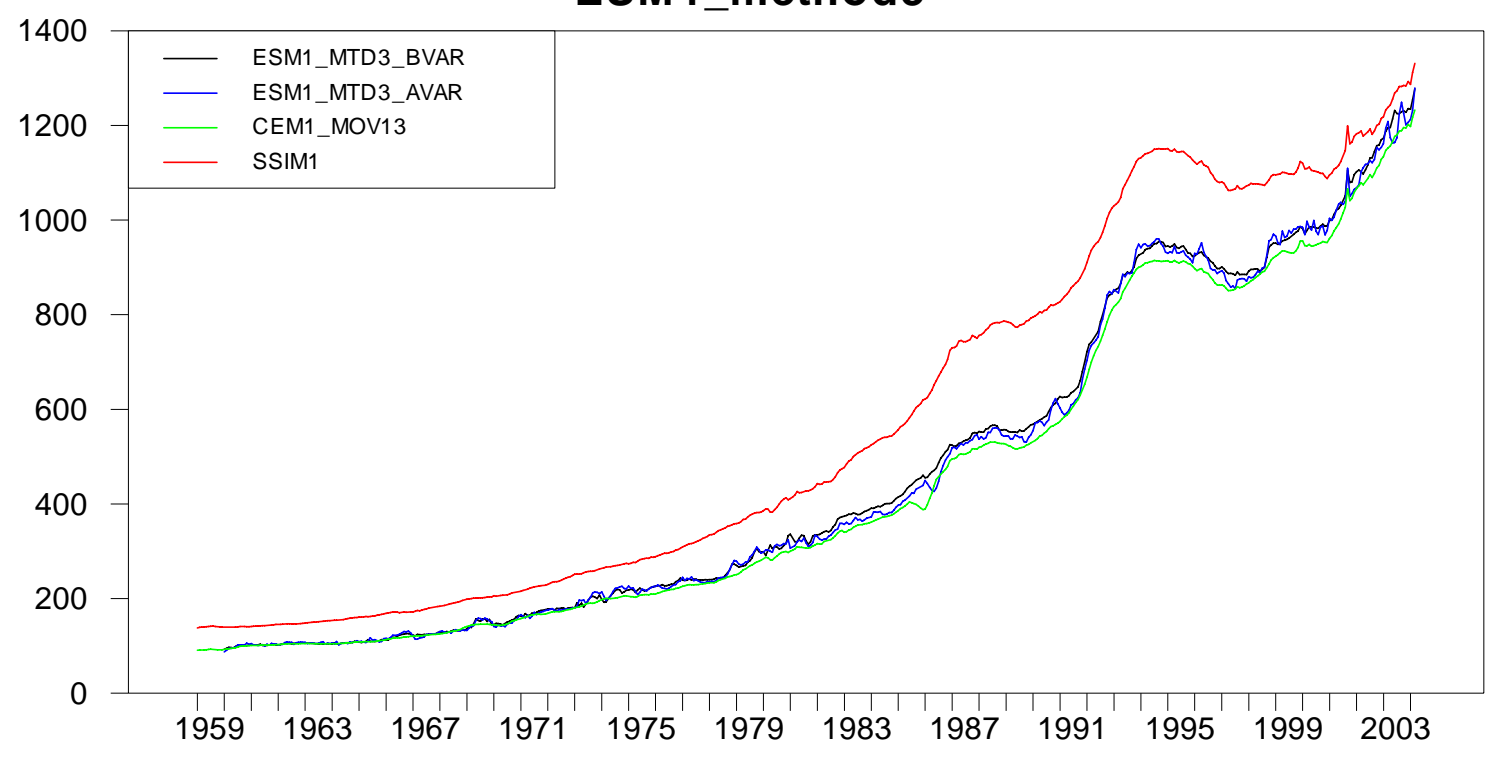

Note: ESM1_mtd3_AVAR: Economic Stock of M1 computed using method 3 and forecasts from AVAR

ESM1_mtd3_BVAR: Economic Stock of M1 computed using method 3 and forecasts from BVAR 
Figure 12:

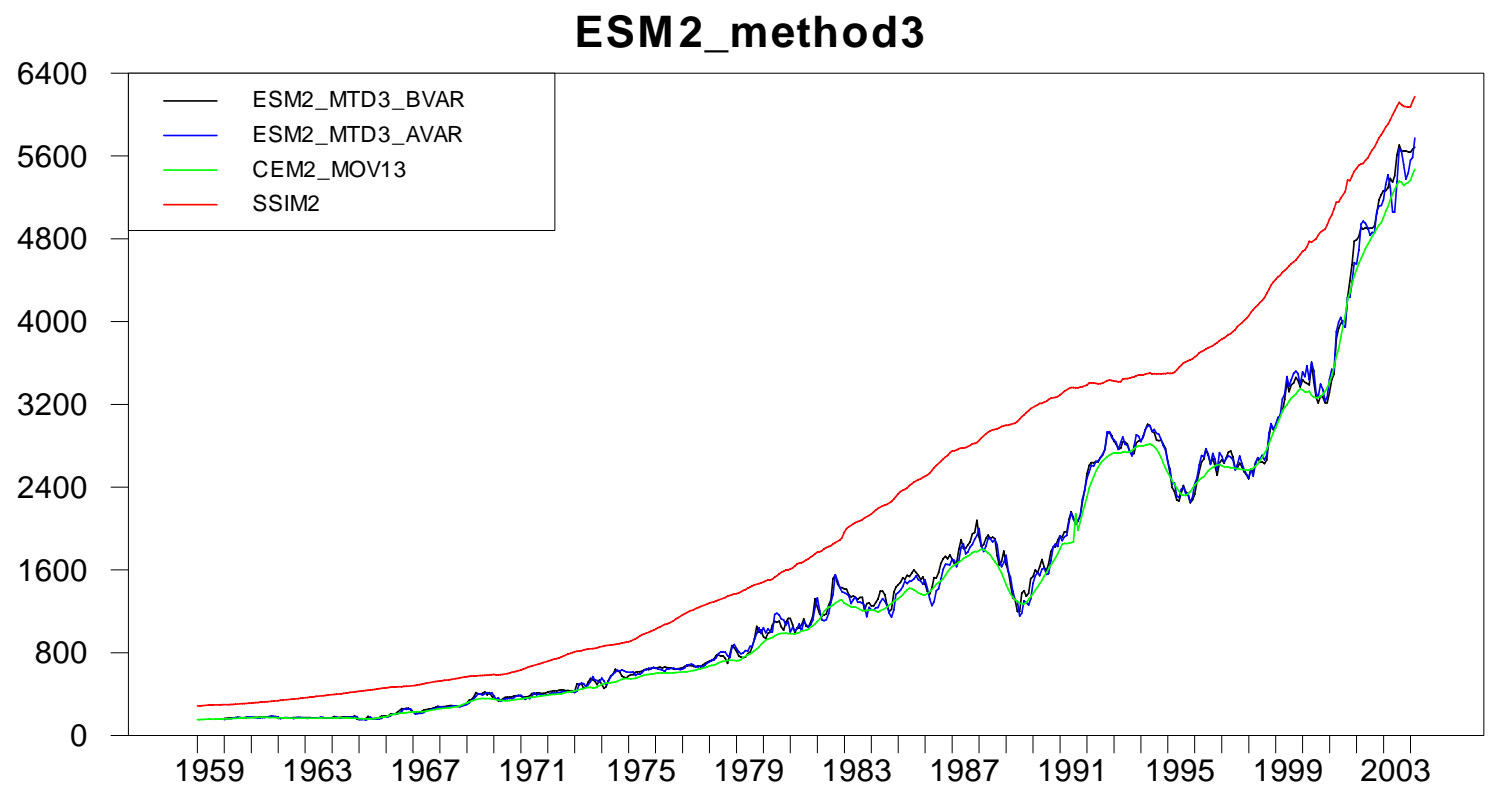

Note: ESM2_mtd3_AVAR: Economic Stock of M2 computed using method 3 and forecasts from AVĀR

ESM2_mtd3_BVAR: Economic Stock of M2 computed using method 3 and forecasts from BVAR 


\section{Figure 13:}

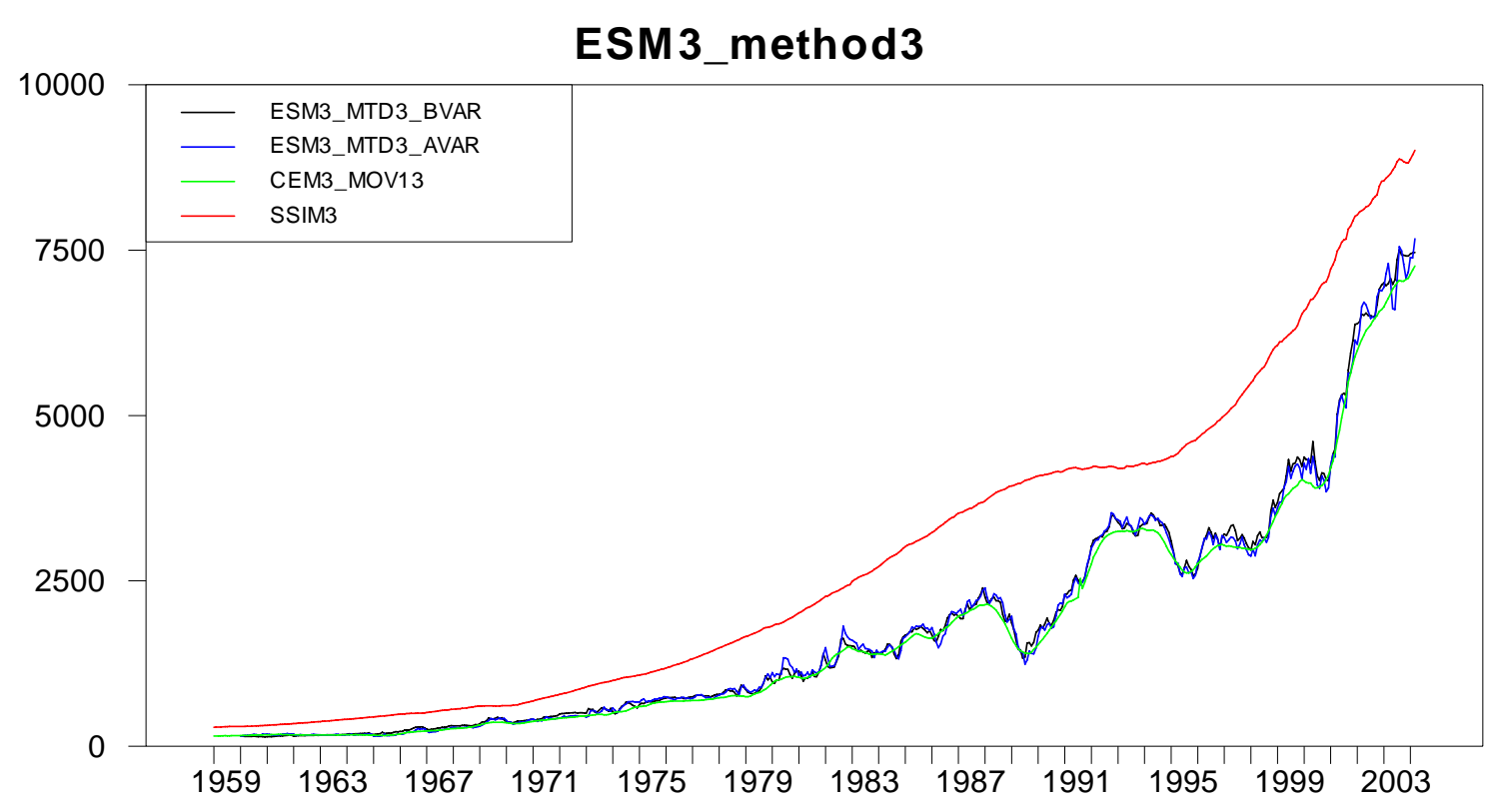

Note: ESM3_mtd3_AVAR: Economic Stock of M3 computed using method 3 and forecasts from AVAR

ESM3_mtd3_BVAR: Economic Stock of M3 computed using method 3 and forecasts from BVAR 
Table 16: Data Availability

\begin{tabular}{|c|c|}
\hline M1 Monetary components & Data availability \\
\hline Currency & $1960<-------------------------------------------~ p$ present \\
\hline Travelers' checks & $1960<-1$ \\
\hline Demand deposits & 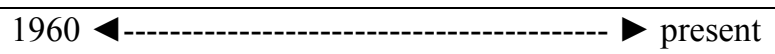 \\
\hline Other checkable deposits at commercial banks & $1974.01<-------->1985.12$ \\
\hline \multicolumn{2}{|l|}{ net of super NOW accounts } \\
\hline Other checkable deposits at thrift institutions & $1960.01<------------------>1985.12$ \\
\hline \multicolumn{2}{|l|}{ net of super NOW accounts } \\
\hline Super now accounts at commercial banks & $1982.12<--1985.12$ \\
\hline Super now accounts at Thrifts Institutions & $1982.12<->1985.12$ \\
\hline Other checkable deposits at commercial banks & $1986.1<$--- present \\
\hline \multicolumn{2}{|l|}{ including super NOW accounts } \\
\hline Other checkable deposits at thrift institutions & $1986.1<$--- present \\
\hline \multicolumn{2}{|l|}{ including super NOW accounts } \\
\hline M2 Monetary components & Data availability \\
\hline \multicolumn{2}{|l|}{ All components in $\mathrm{M} 1$} \\
\hline Money market deposit accounts at commercial banks & $1982.12<--->1991.08$ \\
\hline Money market deposit Accounts at thrift institutions & $1982.12<--->1991.08$ \\
\hline Savings deposits at commercial banks net of money & $1960.01<1991.08$ \\
\hline \multicolumn{2}{|l|}{ market deposit accounts } \\
\hline Savings deposits at thrift institutions net of money & $1960.01<1991.08$ \\
\hline \multicolumn{2}{|l|}{ market deposit accounts } \\
\hline Savings deposits including money market deposit & $1991.09<-->$ present \\
\hline \multicolumn{2}{|l|}{ accounts at commercial banks } \\
\hline Savings deposits including money market deposit & $1991.09<-->$ present \\
\hline accounts at thrift institutions & \\
\hline
\end{tabular}




\begin{tabular}{|l|c|}
\hline Retail money funds & 1973.02 \\
\hline Small denomination time deposits & 1960.1 \\
\hline at the commercial banks & 1960.1 \\
\hline Small denomination time deposits & \\
\hline at the thrift institutions & \\
\hline
\end{tabular}




\begin{tabular}{|c|c|}
\hline M3 Monetary components & Data availability \\
\hline \multicolumn{2}{|l|}{ All components in M2 } \\
\hline Total repurchase agreements & 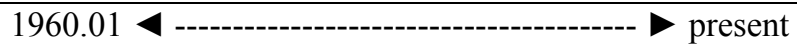 \\
\hline Total Eurodollars & 1960.01 - \\
\hline Total large denomination time deposits & 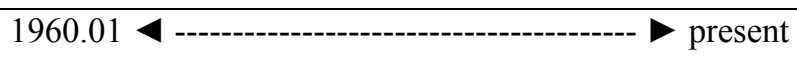 \\
\hline Institutional money funds & 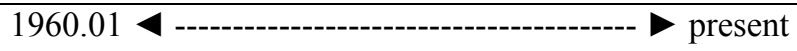 \\
\hline L Monetary components & Data availability \\
\hline \multicolumn{2}{|l|}{ All components in M3 } \\
\hline Savings bonds & 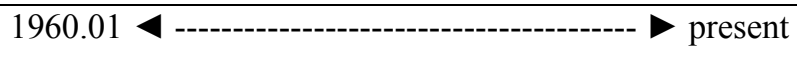 \\
\hline Short term treasury securities & 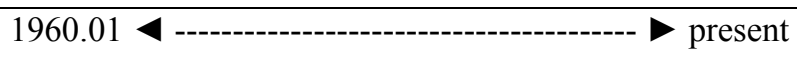 \\
\hline Bankers acceptances & 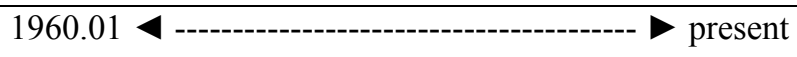 \\
\hline Commercial paper & 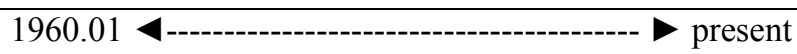 \\
\hline
\end{tabular}




\section{References}

Anderson, R.G., B. Jones, and T. Nesmith. 1997a. "Monetary Aggregation Theory and Statistical Index Numbers." Federal Reserve Bank of St. Louis Review 79(1): 31-51.

Anderson, R.G., B. Jones, and T. Nesmith. 1997b. "Building New Monetary Services Indexes: Concepts, Data, and Methods." Federal Reserve Bank of St. Louis Review 79(1):53-82.

Barnett, W.A., 1978. "The User Cost of Money." Economics Letter 1 145-149. Reprinted in William A.

Barnett and Apostolos Serletis (eds.), 2000, The Theory of Monetary Aggregation, North Holland, Amsterdam, chapter 1, pp. 6-10.

Barnett, W.A., 1980. "Economic Monetary Aggregates: An Application of Aggregation and Index number Theory," Journal of Econometrics 14, 11-48. Reprinted in William A. Barnett and Apostolos Serletis (eds.), 2000, The Theory of Monetary Aggregation, North Holland, Amsterdam, chapter 1, pp. 6-10.

Barnett, W.A., 1982a. "The Optimal level of Monetary Aggregation," Journal of Money, Credit, and Banking 14, 687-710. Reprinted in William A. Barnett and Apostolos Serletis (eds.), 2000, The Theory of Monetary Aggregation, North Holland, Amsterdam, chapter 7, pp. 125-149.

Barnett, W. A., 1982b. "Divisia Indices," In Encyclopedia of Statistical Sciences, N. Johnson and S. Kotz (eds.), New York: John Wiley, 412-415. Reprinted in William A. Barnett and Apostolos Serletis (eds.), 2000, The Theory of Monetary Aggregation, North Holland, Amsterdam, chapter 5, pp. 113-124.

Barnett, W. A., 1983. "Understanding the New Divisia Monetary Aggregate," Review of Public Data Use 11, 349-355. Reprinted in William A. Barnett and Apostolos Serletis (eds.), 2000, The Theory of Monetary Aggregation, North Holland, Amsterdam, chapter 4, pp. 100-108.

Barnett, W. A., 1987, “The Microeconomic Theory of Monetary Aggregation, in W. A. Barnett and K. Singleton (eds.), New Approaches to Monetary Economics, Cambridge U. Press. Reprinted in William A. Barnett and Apostolos Serletis (eds.), 2000, The Theory of Monetary Aggregation, North Holland, Amsterdam, chapter 3, pp. 49-99.

Barnett, W. A., 1991a. "Monitoring Monetary Aggregates Under Risk Aversion" In Monetary Policy on 
the 75th Anniversary of the Federal Reserve System, M.T. Belongia (ed.), Boston: Kluwer Academic, 189-222. Reprinted in William A. Barnett and Apostolos Serletis (eds.), 2000, The Theory of Monetary Aggregation, North Holland, Amsterdam, chapter 11, pp. 217-244.

Barnett, W. A., 1991b. "A Reply to Julio J. Rotemberg." In Monetary Policy on the 75th Anniversary of the Federal Reserve System, M.T. Belongia (ed.), Boston: Kluwer Academic, 232-244. Reprinted in William A. Barnett and Apostolos Serletis (eds.), 2000, The Theory of Monetary Aggregation, North Holland, Amsterdam, chapter 14, pp. 296-306.

Barnett, W. A., 2005, “Multilateral Aggregation-Theoretic Monetary Aggregation over Heterogeneous Countries," European Central Bank Working Paper. No. 260, forthcoming in shorter form in the Journal of Econometrics.

Barnett, W. A., U. Chae, and J. Keating, 2005. "The Discounted Economic Stock of Money with VAR Forecasting," Annals of Finance, forthcoming.

Barnett, W. A., D. Fisher, and A. Serletis, 1992. "Consumer Theory and the Demand for Money," Journal of Economic Literature 30, 2086-2119. Reprinted in William A. Barnett and Apostolos Serletis (eds.), 2000, The Theory of Monetary Aggregation, North Holland, Amsterdam, chapter 18, pp. 389-427.

Barnett, W. A., M. Hinich, and W. Weber, 1986, "The Regulatory Wedge between the Demand-Side and Supply-Side Aggregation Theoretic Monetary Aggregates, Journal of Econometrics, 165-185. Reprinted in William A. Barnett and Apostolos Serletis (eds.), 2000, The Theory of Monetary Aggregation, North Holland, Amsterdam, chapter 19, pp. 433-453.

Barnett, W. A., M. Hinich, and P.Yue, 2000. "The Exact Theoretical Rational Expectations Monetary Aggregate," Macroeconomic Dynamics, June, vol. 4, no. 2, pp. 197-221.

Barnett, W. A. and A. Serletis, eds., 2000, The Theory of Monetary Aggregation, North-Holland, Amsterdam.

Barnett, W. A., E.K. Offenbacher, and P.A.Spindt, 1984. "The New Divisia Monetary Aggregates," Journal of Political Economy 92, 1049-1085. Reprinted in William A. Barnett and Apostolos Serletis (eds.), 2000, The Theory of Monetary Aggregation, North Holland, Amsterdam, chapter 17, 
pp. 360-388.

Barnett, W. A. and S. Wu, 2005, "On the User Costs of Risky Monetary Assets," Annals of Finance, vol 1, no. 1, January, p. 35-50.

Barnett, W. A. and Ge Zhou, 1994. "Partition of M2+ as a Joint Product: Commentary", the Federal reserve Bank of St. Louis Review 76, 53-62. Reprinted in William A. Barnett and Apostolos Serletis (eds.), 2000, The Theory of Monetary Aggregation, North Holland, Amsterdam, chapter 15 , pp. 307-319.

Barth, J. R., A. Kraft, and J. Kraft, 1977. “The 'Moneyness' of Financial Assets,” Applied Economics 9, $51-61$.

Bisignano, J, 1974. “Real Money Substitutes,” Discussion Paper \#17, Federal Reserve Bank of San Francisco.

Blanchard, O. and S. Fischer, 1989, Lectures in Macroeconomics, MIT Press, Cambridge, MA.

Chetty, K. F., 1969. “On Measuring the Nearness of Near-Moneys,” American Economic Review 59, 270-281.

Chetty, K. V., 1972. “On Measuring the Nearness of Near-Moneys: Reply,” American Economic Review 62, 226-229.

Diewert, W. E. 1976. "Exact and Superlative Index Numbers." Journal of Econometrics 4(2), 115-45.

Doan, T., R. B. Litterman, and C.A. Sims, 1984. "Forecasting and Conditional Projection Using Realistic Prior Distributions." Econometric Reviews 3, 1-144.

Donovan, D. J., 1978, “Modeling the Demand for Liquid Assets: An Application to Canada,” International Monetary Fund Staff Papers 25, pp. 676-704.

Ford, J. L. and F. Stark, 1967. Long and Short Term Interest Rates, New York: Augustus M. Kelley.

Friedman, Milton, 1969, “The Optimum Quantity of Money," in Milton Friedman, The Optimum Quantity of Money and Other Essays. Chicago: Aldine Publishing Company, 1969.

Friedman, M. and A. J. Schwartz, 1970. Monetary Statistics of the United States: Estimates, Sources, Methods, and Data, New York: Columbia University Press (for the NBER).

Friedman, M. and D. I. Meiselman, 1963. “The Relative Stability of Monetary Velocity and the Investment 
Multiplier in the United States, 1897-1958.” In Commission on Money and Credit, Stabilization Policies, Englewood Cliffs, N. J.: Prentice Hall.

Green, H. A. J., 1964, Aggregation in Economic Analysis: An Introductory Survey, Princeton, N. J., Princeton University Press.

Gurley, J. 1960. "Liquidity and Financial Institutions in the Postwar Economy," Study Paper \#14, in The Study of Employment, Growth, and Price Levels, U. S. Government Printing Office, Washington, D.C.

Hancock, D, 1991, A Theory of Production for the Financial Firm, Boston: Kluwer Academic.

Hawtrey, R. G., 1930. “Money and Index Numbers,” Journal of the Royal Statistical Society 93, 64-85.

Hoover, Kevin D., and Stephen J. Perez, 1994, "Post Hoc Ergo Propter Once More: An Evaluation of 'Does Monetary Policy Matter? in the Spirit of James Tobin," Journal of Monetary Economics, 34, pp.89-99.

Hutt, W. H., 1983, Keynesianism - Retrospect and Prospect, Chicago: Regnery.

Ireland, Peter. 2001. “The Real Balance Effect,” Working Paper 491, Boston College.

Jorgenson, D. W., 1967. “The Theory of Investment Behavior.” In Determinanats of Investment Behavior, F. Ferber (eds.), New York: Columbia University Press.

Kane, E. J., 1964. "Money as a Weighted Aggregate,” Zeitschrift für Nationalökonomie 25, 221-243.

Keating, J. W. 1993. "Asymmetric Vector Autoregressions" American Statistical Association, Proceedings of the Business and Economic Statistics Section, 68-73.

Keating, J. W. 2000. "Macroeconomic Modeling with Asymmetric Vector Autoregressions" Journal of Macroeconomics 22(1), 1-28.

Klein, B., 1974, “Competitive Interest Payments on Bank Deposits and the Long-Run Demand for Money," American Economic Review 64, 931-949.

Lee, T. H., 1972. "On Measuring the Nearness of Near Moneys: Comment," American Economic Review 62, 217-220.

Litterman, R. B. 1986. "Forecasting with Bayesian Vector Autoregression - Five years of experience," Journal of Business and Economic Statistics 4(1), 25-38. 
Moroney, J. R. and B. J. Wilbratte, 1976. "Money and Money Substitutes," Journal of Money, Credit and Banking 8, 181-198.

Pesek, B. P. and T. R. Savaing, 1967, Money, Wealth, and Economic Theory, New York: Macmillan.

Pigou, A. C., 1943, “The Classical Stationary State,” Economic Journal 53, December, 343-351.

Rotemberg, J. J. 1991. "Commentary: Monetary Aggregates and Their Uses." In Monetary Policy on the 75th Anniversary of the Federal Reserve System, edited by Michael T. Belongia, 223-31. Proceedings of the Fourteenth Annual Economic Policy Conference of the Federal Reserve Bank of St. Louis, October 1989. Boston: Kluwer Academic Publishers.

Rotemberg, J. J., J. C. Driscoll, and J. M. Poterba. 1995. "Money, Output and Prices:Evidence from a New Monetary Aggregate." Journal of Business and Economic Statistics 13(1), 67-83.

Samuelson, P. A. and S. Swamy, 2974. "Invariant Economic Index Numbers and Canonical Duality: Survey and Synthesis," American Economic Review 64, 566-593.

Schunk, D. L., 2001. "The Relative Forecasting Performance of the Divisia and Simple Sum Monetary Aggregates.” Journal of Money, Credit and Banking 33(2), 272-283.

Shiller, R. J., 1979. “The Volatility of Long-Term Interest Rates and Expectations Models of the Term Structure," Journal of Political Economy 37, 1190-1219.

Sims, C. A, 1980. "Macroeconomics and Reality." Econometrica 48 (1), 1-48.

Steinhauer, L. and J. Chang. 1972. “On Measuring the Nearness of Near-Moneys: Comment," American Economic Review 62, 221-225.

Wicksell, K., 1898, Interest and Prices: A Study of the Causes Regulating the Value of Money. London: Macmillan. Translated into English in 1936 by Richard F. Kahn. 